\title{
Commercial Investigation of the Ebullated-Bed Vacuum Residue Hydrocracking in the Conversion Range of 55-93\%
}

\author{
Dicho Stratiev,* Svetoslav Nenov, Ivelina Shishkova, Borislav Georgiev, Georgi Argirov, Rosen Dinkov, \\ Dobromir Yordanov, Vassia Atanassova, Petar Vassilev, and Krassimir Atanassov
}

Cite This: ACS Omega 2020, 5, 33290-33304

Read Online

ABSTRACT: The LUKOIL Neftohim Burgas vacuum residue hydrocracking has increased the vacuum residue conversion from 55 to $93 \%$ as a result of a proper feed selection, optimal catalyst condition, and the use of a Mo nanodispersed catalyst. It was found that the feed colloidal instability index estimated from the feed saturates, aromatics, resins, and asphaltenes (SARA) data negatively correlated with the conversion. Correlations based on the use of the nonlinear least-squares method, which relates the density to the aromatic structure contents for the straight run and hydrocracked vacuum residues, were developed. Intercriteria analysis was applied to evaluate the relations between the different properties of the straight run and the hydrocracked vacuum residual oils. The density of the hydrocracked vacuum residue measured by dilution with toluene was found to strongly correlate with the conversion, Conradson carbon content, softening point, and Fraasss breaking point.

\section{INTRODUCTION}

The efficient use of the mineral source petroleum requires its refining to produce high-value products at minimal costs and have minimal unfavorable effects on the environment. The high-value products are the light oil fractions boiling below 360 ${ }^{\circ} \mathrm{C}$ (naphtha and middle distillates) and, to a lesser extent, the vacuum gas oil, which can be used as a feed for catalytic cracking or as a source for the production of lubricant oils. The light oil fractions can be used for the production of transportation fuels, whose use is expected to decrease to reduce $\mathrm{CO}_{2}$ emissions of $80-95 \%$ by the year 2050 , with respect to the 1990 level, ${ }^{1}$ or as feedstocks for the petrochemical industry. The vacuum residue (VR) is the least valuable and the most unwanted product from petroleum refining. Therefore, the technologies that can convert the vacuum residue into high-value light oil products at the maximum conversion level are welcome in modern petroleum refining. The slurry VR hydrocracking is reported to commercially achieve an average conversion level of $95 \%{ }^{2}$ The ebullated-bed VR hydrocracking was also shown to be capable of achieving $93 \%$ conversion on a commercial scale. ${ }^{3}$ The feed has been found to be the single variable that most affects the performance of vacuum residue hydrocracking. ${ }^{4-6}$ Therefore, characterization of the vacuum residue hydrocracking feed is of utmost importance for the right selection of the petroleum crudes, which can be processed in a refinery possessing residue hydrocracking technology in its processing scheme. However, the characterization of the vacuum residue is not an easy task considering its low volatility, high viscosity, and high melting point. ${ }^{7}$ Even the measurement of the density of the vacuum residues can report incorrect values if no dilution approach is undertaken. ${ }^{8-10}$ One of the most explored ways to characterize the chemical nature of oils and vacuum residues is saturates, aromatics, resins, and asphaltenes (SARA) analysis. $^{11-27}$ The different techniques employed to measure the vacuum residue SARA composition, however, can report different values even for the same samples studied.? Youtcheff, $^{19}$ for example, pointed out that thin-layer chromatography (TLC), also known as Iatroscan, is featured with a separation that has a large amount of error on repeat analysis. For that reason, we performed a study employing four different SARA analysis techniques: LUKOIL Neftohim Burgas (LNB) method, ${ }^{28}$ ASTM D-4124, ${ }^{29}$ high-performance liquid chromatography (HPLC), and TLC-Iatroscan ${ }^{23}$ to evaluate their consistency. We have also used literature data for 139 vacuum residual oils having a very broad range of variations in the SARA composition and relative density $\left(d_{4}^{20}\right)$ between 0.938 and 1.12 , extracted from 22 literature sources. ${ }^{5,6,16,30-49}$ The nonlinear least-squares method was applied to improve the prediction of the vacuum residue aromatic structure content from density since the established relation from our earlier studies ${ }^{9,50}$ used a second-order polynomial fit. The disadvantage of the second-order polynomial fit is that beyond

Received: October 17, 2020

Accepted: November 19, 2020

Published: December 14, 2020 


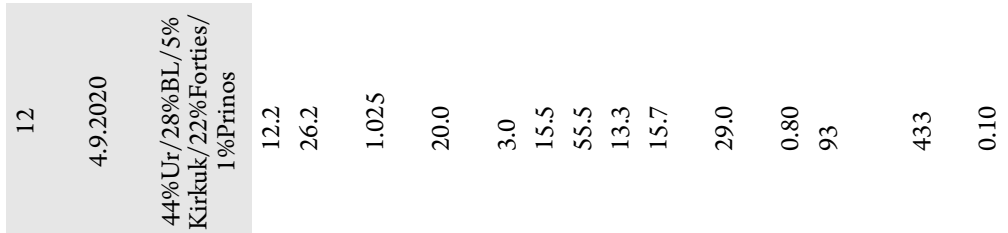

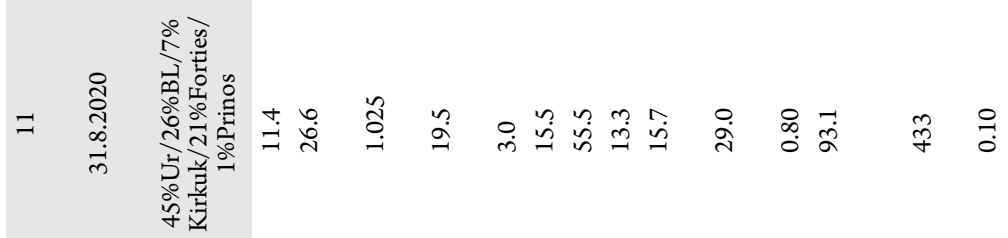

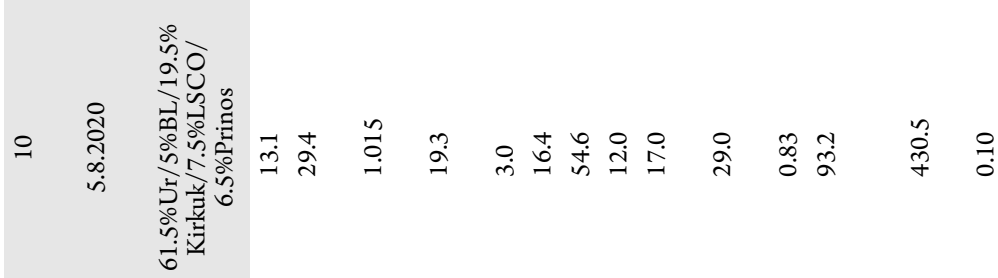

ㅇํㄹ

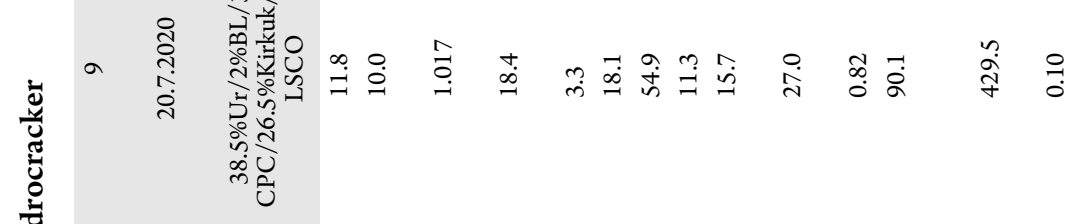

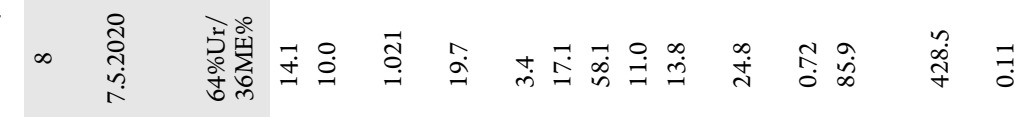

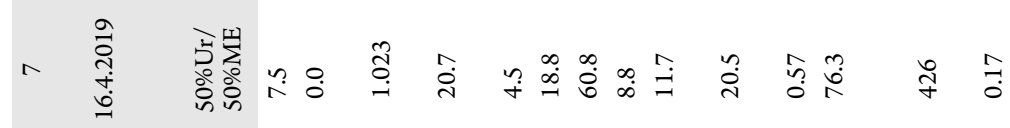

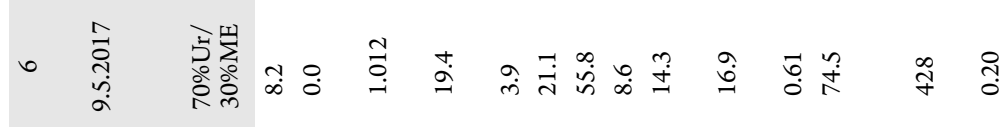

n

+ 产 突

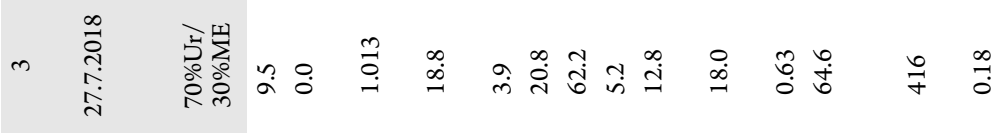

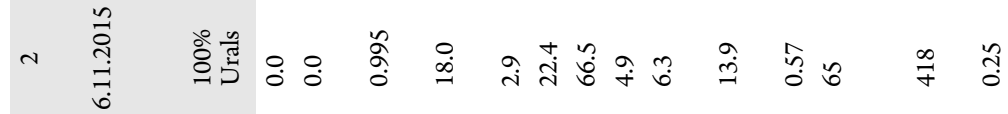

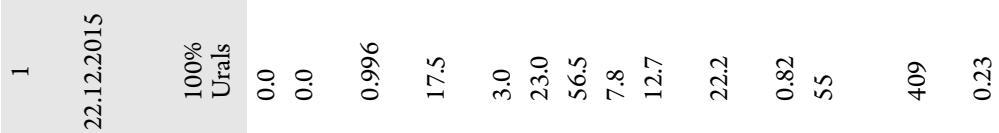

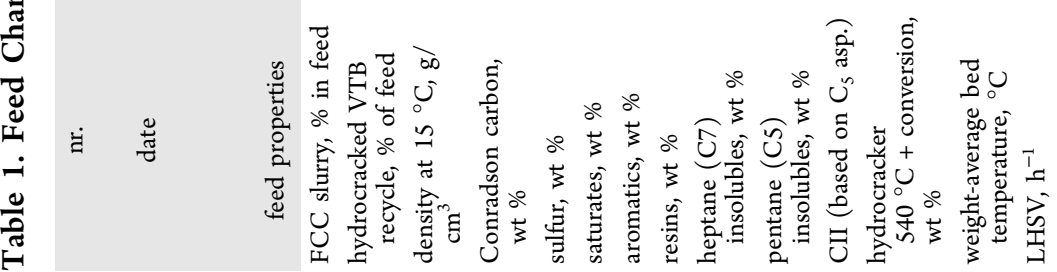




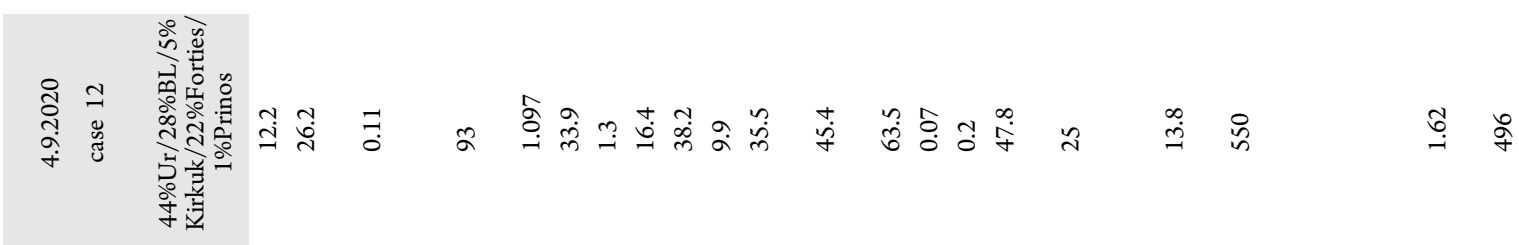

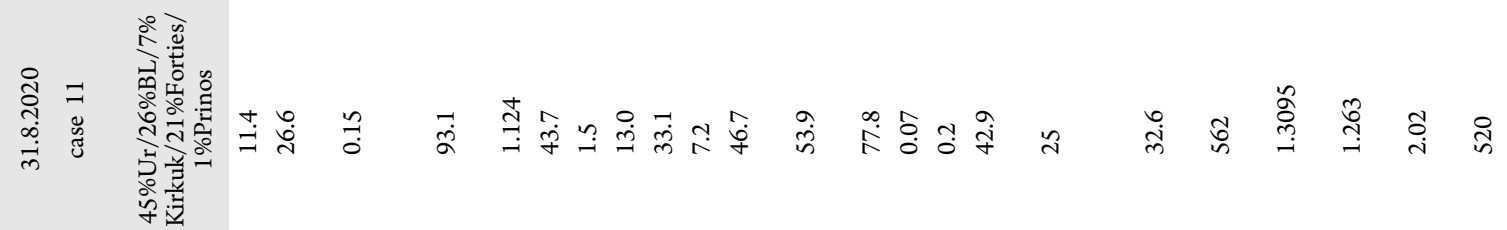

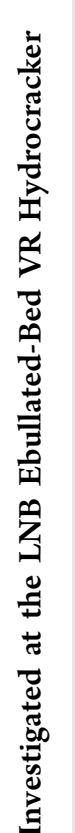

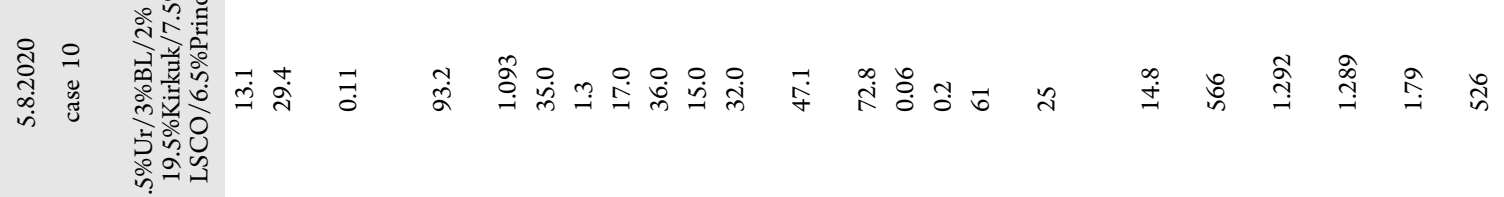
๑)

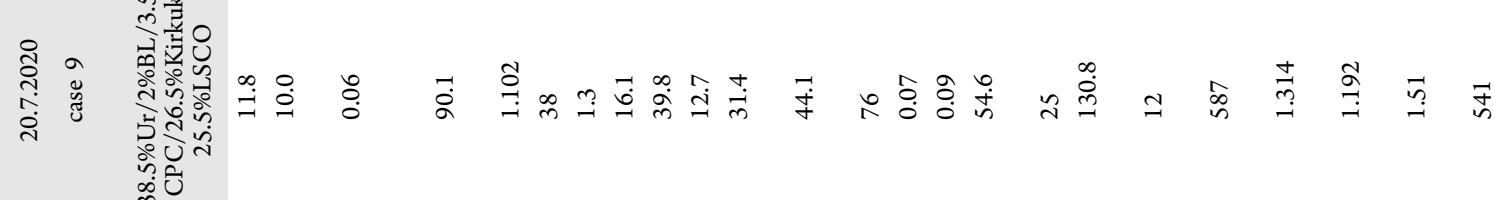

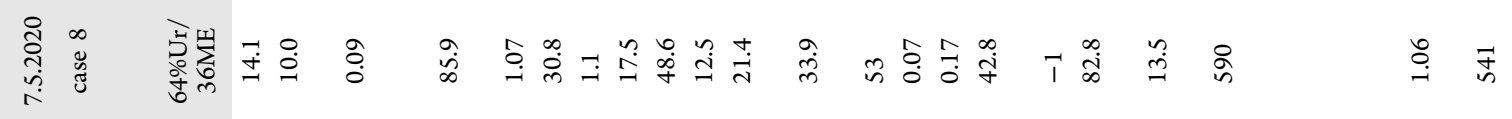

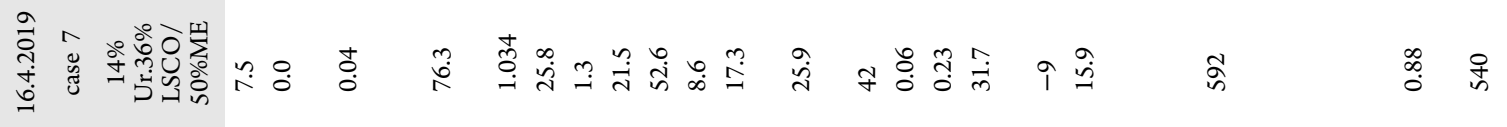

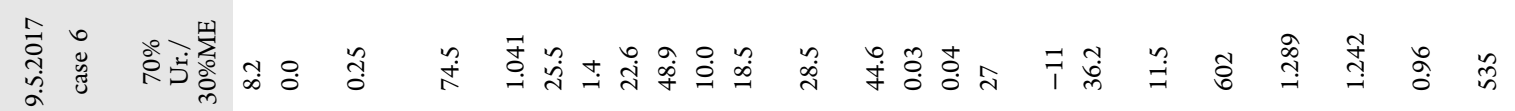

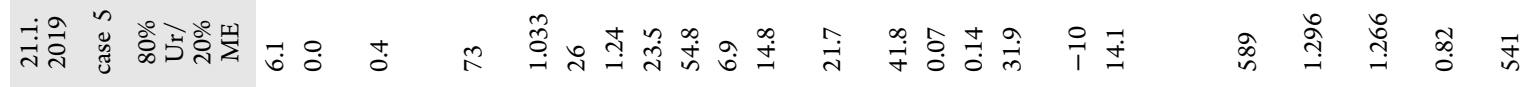

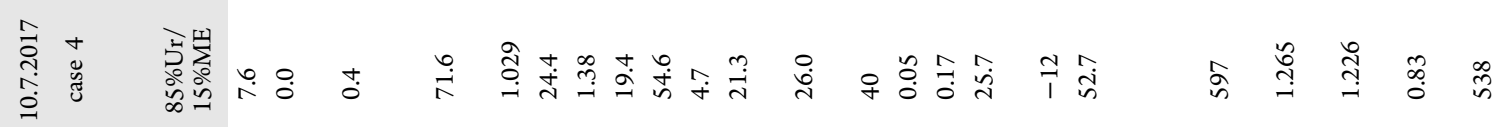

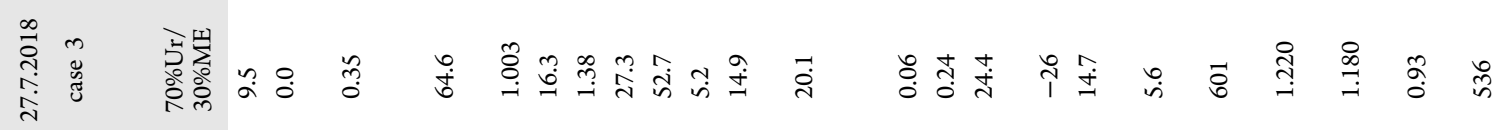

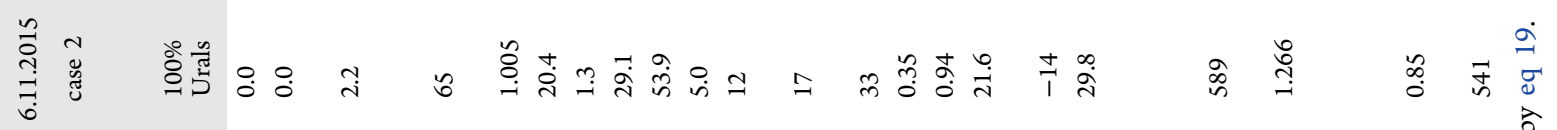

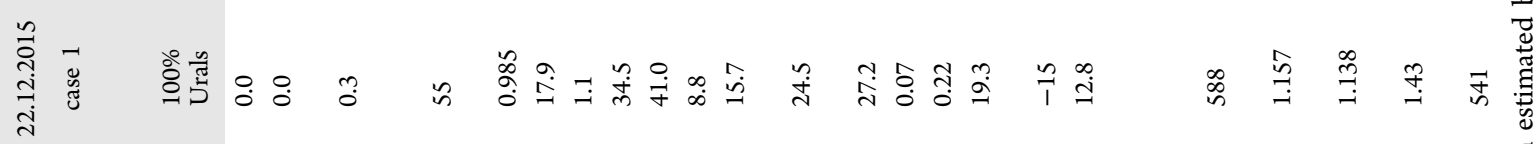




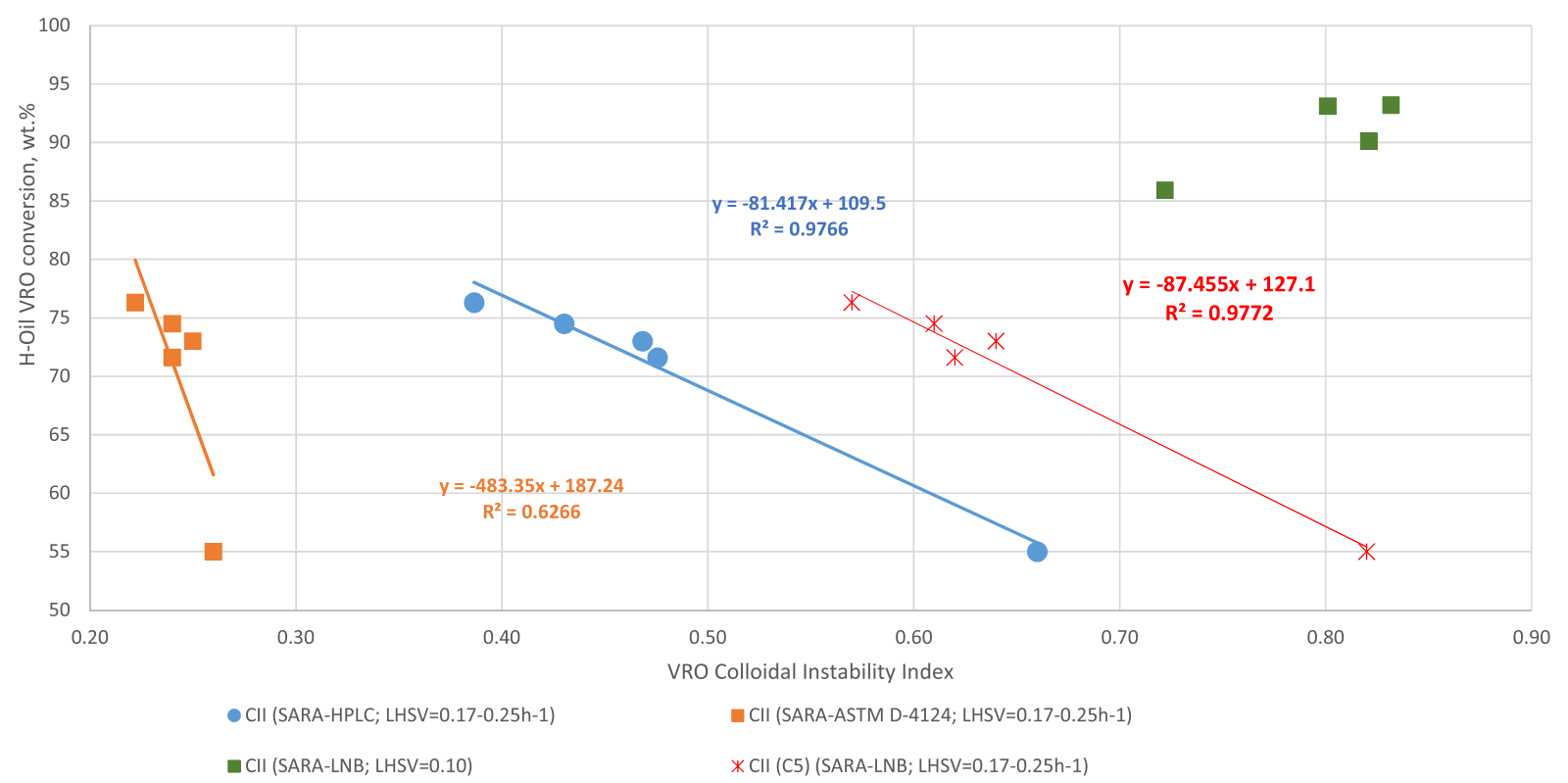

Figure 1. Relation of the VR feedstock colloidal instability index (CII) to the observed VR conversion at the LNB commercial hydrocracker.

the maximum density for which this regression is developed, the predicted aromatic structure content starts to decrease with a further increase of the density, which is unrealistic. The data we used in our earlier studies contained vacuum residues whose maximum $d_{4}{ }^{20}$ was 1.07 . Intercriteria analysis (ICrA) was also used in this study to evaluate the data of VR characterization aiming at finding the statistically meaningful relations and define the degree of similarity between the different vacuum residual oils. ICrA is distinguished from the typical correlation analysis, giving the opportunity to quantitatively determine the degree of similarity between subjects, which have multiple different characteristics. In this way, the potential vacuum residue candidates for processing in the LNB hydrocracker can be quantified as to how far or how close they are to the vacuum residues, which are known as worst performers or to those known as the best performers.

Regardless of the very high level of conversion achieved in a LUKOIL Neftohim Burgas (LNB) commercial ebullated-bed VR hydrocracker, which is not achievable by carbon rejection technologies, there is still hydrocracked vacuum residue remaining whose further utilization needs to be addressed. LNB, being one of the most complex refineries worldwide according to the Solomon Associates fuels study, has performed several investigations devoted to the use of the hydrocracked VR as a feedstock for the production of road pavement bitumen. ${ }^{50-54}$ It turned out, however, that the hydrocracked VR, designated as vacuum tower bottom (VTB), altered its properties from study to study. ${ }^{51-54}$ Initially, it was found that the hydrocracked VTB can be used as a feedstock for the production of road asphalt in concentrations of about $15-20 \%$ of the total road asphalt feed. ${ }^{51}$ Later, by modification of the road asphalt feed blend by addition of sulfur, the share of hydrocracked VTB in the road asphalt feed blend was increased to $70 \% .^{53-55}$ However, on further increase of the VR conversion, a consequence of the use of the nanodispersed catalyst $^{56}$ was found to affect the hydrocracked VTB quality as a feedstock for the production of road asphalt. ${ }^{55}$

The aim of this study is to investigate the application of the different SARA analysis techniques and to relate the SARA analysis data to the commercial ebullated-bed VR hydrocracker performance and to investigate the evolution of the hydrocracked vacuum residues in the conversion range of 55-93\%.

\section{RESULTS AND DISCUSSION}

The licensor of ebullated-bed vacuum residue hydrocracking (EBVRHC) defines the conversion range variation between 50 and $85 \%$ depending on the feedstock. ${ }^{60}$ The LNB hydrocracker went beyond the upper limit reaching $93 \%$ conversion. ${ }^{3}$ This improvement was achieved by proper feedstock selection, ${ }^{6}$ improved catalyst condition, ${ }^{61}$ use of the nanodispersed catalyst, ${ }^{56}$ and optimization of the process conditions. $^{3}$ Our earlier study ${ }^{57}$ has shown that the colloidal instability index (CII) best correlates with the conversion level in the commercial LNB hydrocracker. Three different SARA techniques (LNB method; ${ }^{28}$ ASTM D-4124; ${ }^{29}$ and highperformance liquid chromatography (HPLC)) were employed to estimate the CII for the cases where the liquid hourly space velocity (LHSV) varied between 0.17 and $0.25 \mathrm{~h}^{-1}$ (cases 1, 4, 5 , 6, and 7 from Table 1). For all other cases, the LNB SARA method $^{28}$ was used to characterize both feed and hydrocracked VTB products (Table 2). The data in Figure 1 indicate that for all three methods, the decrease of the feed CII is associated with an increase in the conversion. The $\mathrm{CII}$ is estimated by the expression as defined in ${ }^{62,63}$

$$
\mathrm{CII}=\frac{\text { saturates }+ \text { asphaltenes }}{\text { aromatics }+ \text { resins }}
$$

The data in Figure 1 show that at an LHSV of $0.10 \mathrm{~h}^{-1}$, irrespective of the higher value of the feed CII, the conversion level is very high. The reason for the higher value of the CII for cases $8-12$ is the involvement of recycling of the hydrocracked VTB product in the total hydrocracker feed. As evident from the data in Figure S1, the hydrocracked VTB product has a higher CII than the feed. Regardless of the higher CII and the processing of recycling of hydrocracked VTB, cases 8-12 were featured with a very low atmospheric tower bottom product (ATB) sediment content $\sim 0.1 \%$ (Table 2 ). The only explanation for the reduced sediment formation independent of the worsened feed quality is the lower LHSV, which is 2.5 


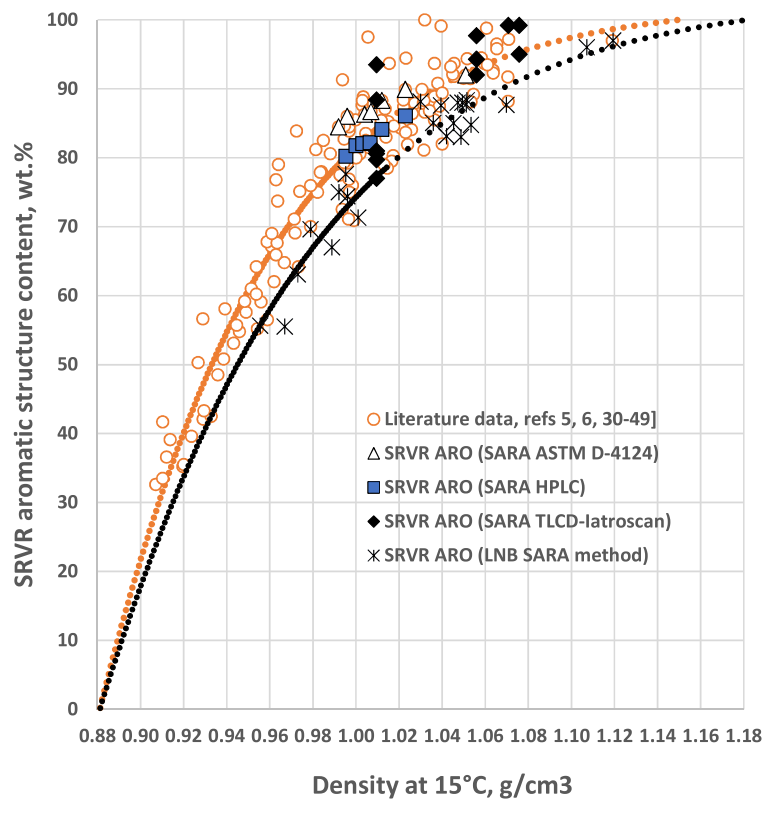

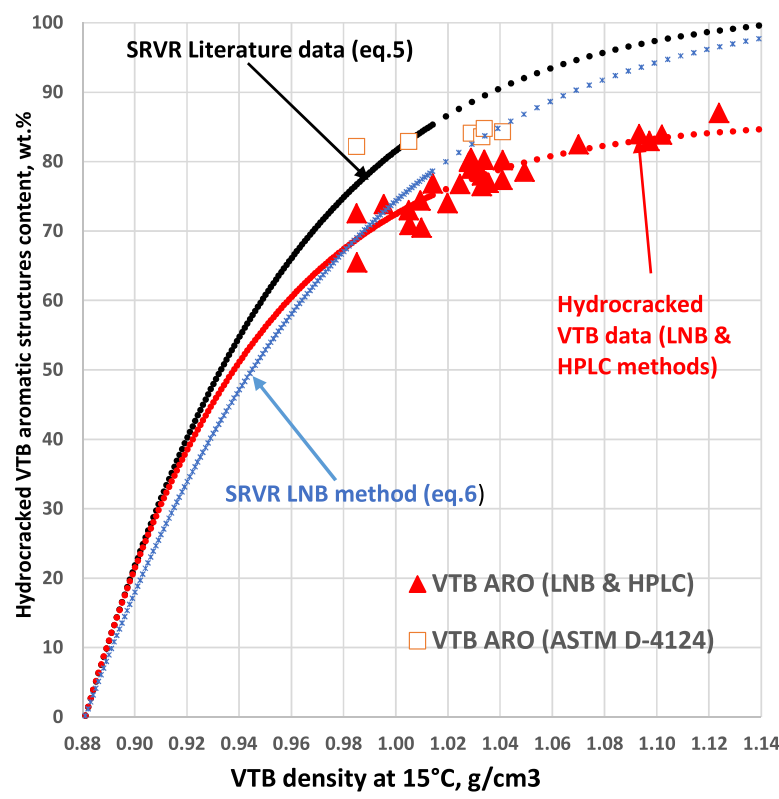

Figure 2. Dependence of the VR aromatic structure (aromatic, resin + asphaltene fractions) content on the VR density for SRVR (a) and hydrocracked VTB (b).

times as low as that of the design LHSV. The clear dependence of the conversion in the commercial LNB ebullated-bed vacuum residue hydrocracker on the CII for the LHSV in the range of $0.17-0.25 \mathrm{~h}^{-1}$ when the catalyst condition is optimal has been established for more than 30 vacuum residue feeds. However, the question that arises is whether the SARA analysis data are consistent because the CII, as shown in eq 1 , is estimated from the SARA analysis data. The established relation of the vacuum residue density to the aromatic structure content $(=100$ - saturates content, wt \%) could be used as a tool to evaluate the consistency of the SARA analysis data. As already mentioned in the Introduction section, the earlier developed correlations relating the VR density to the aromatic structure content were based on a second-order polynomial and the maximum relative density $\left(d_{4}^{20}\right)$ of the vacuum residue used to develop the regression was 1.07 . $^{9,50}$ After reviewing the properties of about 5000 vacuum residues originating from petroleum crudes all over the world, we determined that the vacuum residues may have relative densities $\left(d_{4}{ }^{20}\right)$ in the range of $0.938-1.18$. The lowest density of vacuum residue was that of Daqing crude oil (China), and the highest was that of Tempa Rossa (Italy). In fact, the measurement of the Tempa Rossa vacuum residue density with the dilution method performed in the LNB Research Laboratory reported a value of $1.1195 \mathrm{~g} / \mathrm{cm}^{3}$ at 15 ${ }^{\circ} \mathrm{C}$. The data in Table S1 encompass both Daqing and Tempa Rossa vacuum residues SARA data. To the best of our knowledge, all possible variations in SARA compositions of vacuum residues is included in the data of Table S1, which consists of 139 vacuum residues. Besides the data in Table S1, data for straight run vacuum residue (SRVR) (LNB SARA method), hydrocracked VR oils (LNB SARA method) reported in our earlier research ${ }^{9}$ and in this study, and three other SARA methods, ASTM D-4124, high-performance liquid chromatography (HPLC), and thin-layer chromatography (TLC)-Iatroscan, were processed by the nonlinear leastsquares method to construct three functions $f_{1}, f_{2}$, and $f_{3}$ of
VR aromatic structure content from the VR density such that the functions fi are monotonically increasing, $i=1,2,3$.

There exists a point $x_{0}$ in the interval $\left[0.8,0.9 \mathrm{~g} / \mathrm{cm}^{3}\right]$ such that $f_{i}\left(x_{0}\right)=0$ (aromatic structure content $=0$ ) for $I=1,2,3$. This interval was defined by the values for the density of different SARA fractions reported in previous studies. ${ }^{16,64-66}$

$$
f_{i}(x)<100 \text { for all } x \in\left[x \_0, \infty\right]
$$

The function $f_{i}$ approximates data $x_{i}$ (density), $y_{i}$ (aromatic structure content) from Data $i, i, I=1,2,3$ (mentioned above).

For the model function $f_{i}$, we consider a logistic function in the form

$$
f_{i}\left(x ; a_{i}, b_{i}, c_{i}, d_{i}\right)=\frac{100}{c_{i}+a_{i} \exp \left(-b_{i} x\right)}-d_{i}, i=1,2,3
$$

where $a_{i}, b_{i}, c_{i}$, and $d_{i}$ are constants. Let us set $\left(x_{0}\right.$ is any real number)

$$
d_{i}=\frac{100}{c_{i}+a_{i} \exp \left(-b_{i} x_{0}\right)}, \quad i=1,2,3
$$

Then, obviously $f_{i}\left(x_{0}\right)=0$.

Therefore, we have to solve the following $\mathrm{min}-\mathrm{min}$ problem

$$
\begin{gathered}
\min _{x_{0}}\left\{\min _{a_{1}, b_{1}, c_{1}}\left\{\sum_{i=1}^{107}\left(y_{i}-f_{1}\left(x_{i}\right)\right)^{2}\right\}\right. \\
+\min _{a_{2}, b_{2}, c_{2}}\left\{\sum_{i=1}^{21}\left(y_{i}-f_{2}\left(x_{i}\right)\right)^{2}\right\} \\
\left.+\min _{a_{3}, b_{3}, c_{3}}\left\{\sum_{i=1}^{20}\left(y_{i}-f_{3}\left(x_{i}\right)\right)^{2}\right\}\right\}
\end{gathered}
$$

We use the computer algebra system Maple (and GlobalOptimization Toolbox) to solve numerically the obtained 


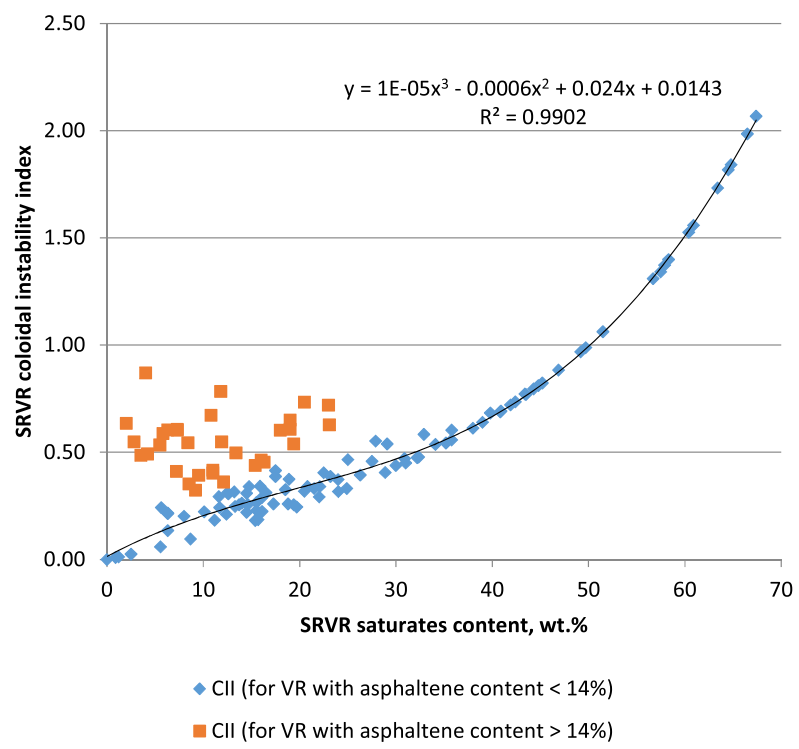

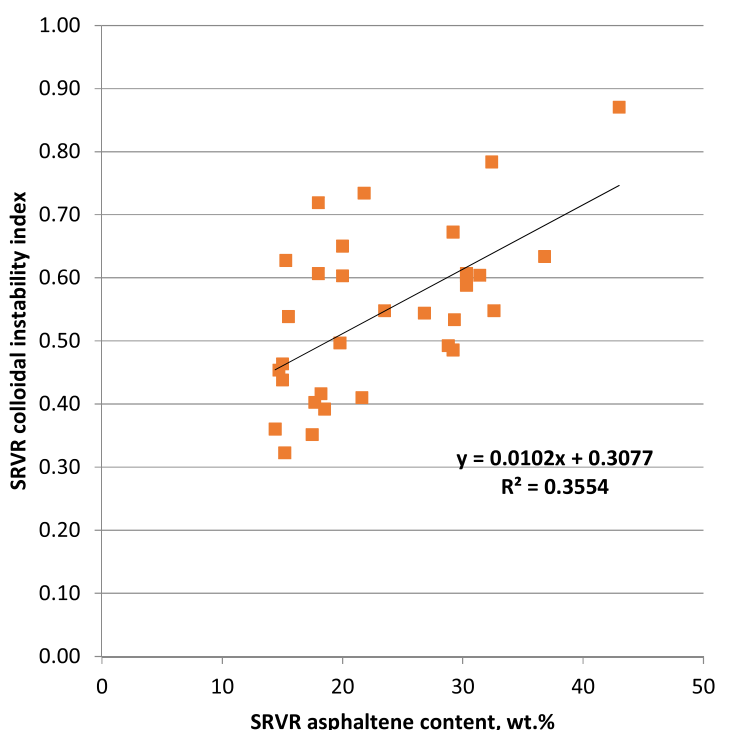

b

Figure 3. Relation of saturate content with the CII for SRVRs having lower than $14 \%$ asphaltenes (a), and the relation of asphaltene content with the CII for SRVRs having more than $14 \%$ asphaltenes (b).

nonlinear min-min problem. As a global search algorithm, we used a differential evolution method (see ref 67 and references therein).

The following expressions were obtained for the VR aromatic structure content dependence on the VR density for the literature data from Table S1 (eq 5), for the LNB SARA method for SRVR (eq 6), and for the LNB SARA method for the hydrocracked VR (eq 7)

$$
\begin{aligned}
\mathrm{ARO} 1= & \frac{100}{0.14784226+9167.6983 \mathrm{e}^{-14.481246} d} \\
& -573.92613 \\
\mathrm{ARO} 2= & \frac{100}{0.16137823+1000 \mathrm{e}^{-11.732948} d}-515.99989 \\
\mathrm{ARO} 3= & \frac{100}{0.075425564+6565.5147 \mathrm{e}^{-15.937044} d} \\
& -1239.6474
\end{aligned}
$$

where ARO1 is the aromatic structure content of SRVR from the literature data from Table $\mathrm{S} 1$, wt \%; ARO2 is the aromatic structure content of SRVR from the LNB SARA method, wt \%; ARO3 is the aromatic structure content of the hydrocracked VR from the LNB SARA method, wt \%; and $d$ is the relative density, $d_{4}^{20}$.

The zero content of the aromatic structures by eqs $2-4$ was found to correspond to the VR density of $0.881 \mathrm{~g} / \mathrm{cm}^{3}$. This value was obtained by the solution of eq 4 . The value of 0.881 $\mathrm{g} / \mathrm{cm}^{3}$ corresponding to zero aromatic structure content in the VR oils is in good agreement with the density of the saturate components of VR oils reported in the literature. ${ }^{16,64-66} \mathrm{We}$ consider that it is reasonable to assume that the three curves, described by eqs $5-7$, should have the same zero content of aromatic structures at the same density because in the LNB SARA method, ${ }^{28}$ the saturate compounds are deemed to be the components that have refractive index $n_{\mathrm{d}}{ }^{20} \leq 1.49$. By the use of eq 6a from the work of Yarranton et al., ${ }^{10}$ for $n_{\mathrm{d}}{ }^{20}=1.49$, $\rho_{20}$ of $0.882 \mathrm{~g} / \mathrm{cm}^{3}$ is obtained. Thus, the value of $0.881 \mathrm{~g} / \mathrm{cm}^{3}$ for zero aromatic structure content seems reasonable.

Figure 2 presents the graphs of the dependence of SRVR and the hydrocracked VTB product on the density. The dotted lines are the predicted, by eqs 5 and 6, aromatic structure contents for SRVRs (Figure 3a) and the predicted, by eq 7 , aromatic structure contents for the hydrocracked VTB product (Figure $3 \mathrm{~b}$ ). The data in Figure 2a also include data from the four investigated SARA methods (ASTM D-4124, HPLC, TLC-Iatroscan, and the LNB method). The HPLC data lie exactly on the curve of eq 4 with an average absolute deviation $(\mathrm{AAD})$ of $0.7 \%$ and a maximum deviation (MD) of $1.2 \%$ for five samples. ASTM D-4124 gives an AAD of 3.4\% and an MD of $5.6 \%$ for six samples. TLC-Iatroscan gives an $\mathrm{AAD}$ of $4.0 \%$ and an MD of $9.3 \%$ for 12 samples. The LNB SARA method is biased from the literature data and is well predicted by eq 6 with an $\mathrm{AAD}$ of $2.4 \%$ and an $\mathrm{MD}$ of $5.4 \%$ for 25 samples. In general, it is evident from the data in Figure 2 that eqs 5-7 very well describe the dependence of the VR aromatic structure content on the density. The accuracy of the prediction of the aromatic structure content for the three data sets and eqs 5-7 is summarized in Table S2. Equation 5 is characterized by the highest average absolute deviation (AAD), which can be explained by the use of data from different SARA methods employed in different parts of the world and reported in the literature. Nevertheless, the data in Figure 2 show that the majority of the literature data lie on the curve of eq 5 . These equations can be used as a tool to verify the correctness of SARA analysis performance. For example, data for Rhemoura VR that exhibited poor performance in the hydrocracker (CII > 1.0), shown in Table S3, exhibited unexpected high content of saturates and low content of aromatic structures in contrast to the estimated values by eq 6 based on the Rhemoura VR density value. The second measurement was much closer to the estimated values, and the difference between the saturate contents of the first and second measurements was $5.4 \%$, which was much higher than the repeatability of the LNB SARA method of \pm 2 wt \% as reported 


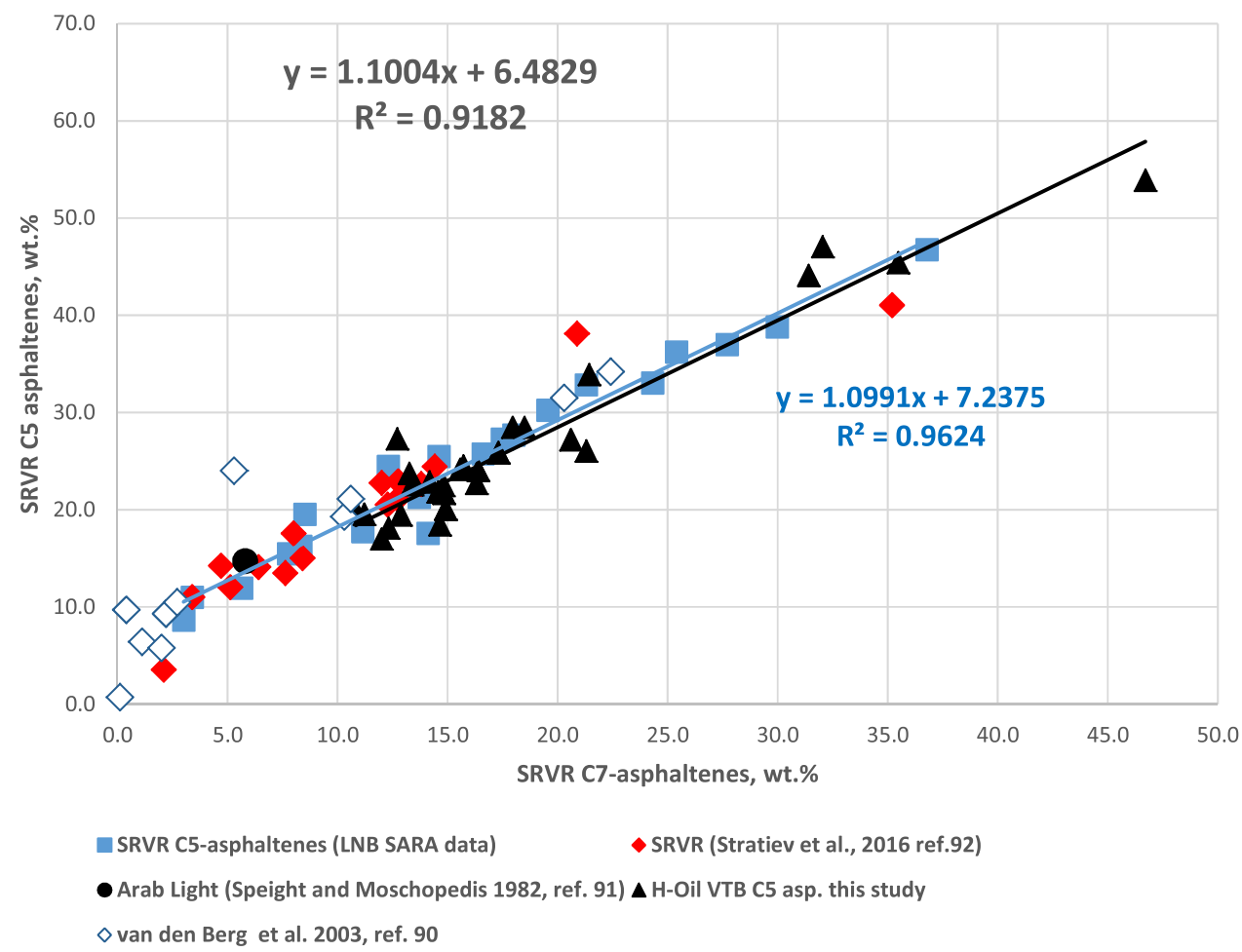

Figure 4. Relation of $\mathrm{C}_{5}$ to $\mathrm{C}_{7}$ asphaltenes for straight run (SRVR) and hydrocracked (VTB) vacuum residual oils.

in ref 28. Equation 6 in that case was used as a tool to find the incorrect performance of the SARA analysis. We could suggest that when the aromatic structure content deviates more than $4 \%$ from that estimated from the density, measured by the dilution method $^{28,57}$ and eqs $5-7$, the SARA analysis is recommended to repeat.

The data in Figure $2 \mathrm{~b}$ show that the hydrocracked VTB aromatic structure content is lower than that of the SRVR. This can explain the higher CII of the hydrocracked VTB, which is partly because of the higher VTB saturate content. The data from ASTM D-4124 did not show a relation with the density, while both the LNB SARA method and HPLC exhibited a strong relation to the hydrocracked VTB density, as described by eq 7 .

Several correlations have been developed in LNB that relate the SRVR density to other SRVR properties. They are summarized below

$$
\mathrm{CCR}=145.38 d-128.69, \quad R^{2}=0.942
$$

(based on data for 30 SRVRs having density variation between 0.956 and $1.119 \mathrm{~g} / \mathrm{cm}^{3}$ and Conradson carbon content variation between 9.2 and 34.3 wt $\%)^{5}$

$$
\begin{gathered}
f_{A}=-0.55823 \times 11.016 \mathrm{e}^{-1.954 d}+1.1649, \\
R^{2}=0.9365
\end{gathered}
$$

Source: Adapted with permission from Mitkova et al. 5 . Copyright [2017, Professor Marin Drinov Publishing House of Bulgarian Academy of Sciences].

$$
\text { dasp }=1.1219 d+0.0089, \quad R^{2}=0.932
$$

(based on data for 20 SRVRs having density variation between 0.956 and 1.107 and $C_{5}$ aphaltene density variation between 1.070 and $1.276 \mathrm{~g} / \mathrm{cm}^{3}$ ). where CCR is the Conradson carbon content of the SRVR, wt \%; $f_{\mathrm{A}}$ is the aromatic carbon fraction; $d$ is the SRVR density at $15{ }^{\circ} \mathrm{C}, \mathrm{g} / \mathrm{cm}^{3}$; and dasp is the density of $\mathrm{C}_{5}$ asphaltenes at $15{ }^{\circ} \mathrm{C}, \mathrm{g} / \mathrm{cm}^{3}$.

Guo et al. $^{43}$ developed a correlation relating the total ring number $\left(R_{\mathrm{T}}\right)$, that is, the sum of naphthenic and aromatic rings, to the VR Conradson carbon content (CCR). It has the form $^{43}$

$$
\mathrm{RT}=\frac{\mathrm{CCR}+1.4159}{2.3124}, \quad R^{2}=0.854
$$

Source: Reprinted with permission from Guo et al. $^{43}$ Copyright [2010, American Chemical Society/Copyright American Chemical Society].

Assuming that the SRVR can be considered as a regular solution of SARA fractions, and by employing eq 10, the density of the aromatic+resin fraction can be estimated, considering that the saturate fraction density is 0.881 , as already established, by the equation

$$
\text { density of aromatics }+ \text { resins }=\frac{\text { aromatic }+ \text { resins }}{\frac{100}{d}-\frac{\text { Sat }}{0.881}-\frac{\text { Asp }}{\text { dasp }}}
$$

where aromatic + resins is the content of aromatic and resin fractions from SARA analysis data, wt \%; Sat is the saturate content, wt \%; and Asp is the asphaltene content, wt \%.

Figure S2 shows the graphs of the relations of the SRVR density with the asphaltene density, aromatic carbon fraction, and total ring number (data based on measurements performed in the LNB Research laboratory and using eqs $8-12)$ and to the aromatic + resin density, aromatic carbon fraction, and total ring number. These data are in agreement with the reports that the asphaltenes are the most aromatic fraction in crude oil. ${ }^{68-70}$ They also show that both asphaltenes and the remaining aromatic structures (aromatics 
Table 3. Best and the Worst Expected Performers in the EBVRHC Based on ICrA Analysis for the SRVRs Whose Properties are Given in Table $\mathrm{S}^{a}$

\begin{tabular}{|c|c|c|c|c|c|c|c|c|c|c|c|c|c|}
\hline $\mathrm{Nr}^{*}$ & $\begin{array}{l}\text { vacuum } \\
\text { residues }\end{array}$ & $\begin{array}{c}\text { relative } \\
\text { density } \\
\left(d_{20}{ }^{4}\right)\end{array}$ & saturate & aromatics & resins & asphaltenes & $\begin{array}{c}\text { aromatic } \\
\text { structures }\end{array}$ & $\begin{array}{l}\text { estimated } \\
\text { ARO, wt \% }\end{array}$ & $\begin{array}{l}\text { Est. } \\
\text { Asp. } \\
\text { D15 }\end{array}$ & $\begin{array}{c}\text { Est. } \\
\text { Aro + Res. } \\
\text { D15 }\end{array}$ & $\begin{array}{l}\text { Asp, \% in } \\
\text { ARO str. }\end{array}$ & CII & $\mu$ \\
\hline \multicolumn{14}{|c|}{ Best Expected Performers } \\
\hline 1 & Shengli & 0.9724 & 16.1 & 30.6 & 51.1 & 2.2 & 83.9 & 71.8 & 1.100 & 0.990 & 2.6 & 0.22 & 0.98 \\
\hline 139 & Arab light & 1.022 & 11.6 & 48.6 & 32.1 & 7.7 & 88.4 & 87.2 & 1.155 & 1.034 & 8.7 & 0.24 & 0.98 \\
\hline 3 & Saudi light & 1.005 & 16.5 & 49.5 & 26.8 & 7.3 & 83.6 & 82.9 & 1.136 & 1.026 & 8.7 & 0.31 & 0.98 \\
\hline 4 & $\begin{array}{l}\text { Saudi } \\
\text { medium }\end{array}$ & 1.0258 & 15.9 & 40 & 33.7 & 9.3 & 83 & 88.0 & 1.160 & 1.032 & 11.2 & 0.34 & 0.98 \\
\hline 5 & Iranian light & 1.0057 & 18.5 & 44.8 & 30.6 & 6.1 & 81.5 & 83.2 & 1.137 & 1.032 & 7.5 & 0.33 & 0.98 \\
\hline 23 & $\begin{array}{l}\text { Columbian } \\
\text { VR2 }\end{array}$ & 1.0118 & 14.6 & 42.3 & 37.2 & 5.8 & 85.3 & 84.8 & 1.144 & 1.030 & 6.8 & 0.26 & 0.99 \\
\hline \multicolumn{14}{|c|}{ Worst Expected Performers } \\
\hline 17 & Resid A & 1.0546 & 10.8 & 48.4 & 11.1 & 29.2 & 88.7 & 92.8 & 1.192 & 1.025 & 32.9 & 0.67 & 0.96 \\
\hline 18 & Resid B & 1.0706 & 11.8 & 45 & 11.4 & 32.4 & 88.8 & 94.8 & 1.210 & 1.059 & 36.5 & 0.78 & 0.98 \\
\hline 36 & Venezuela 2 & 1.0167 & 20.5 & 38 & 19.6 & 21.8 & 79.4 & 86.0 & 1.150 & 1.026 & 27.5 & 0.73 & 0.98 \\
\hline 132 & Maya & 1.040 & 18 & 17 & 40 & 25.0 & 82 & 90.6 & 1.176 & 1.047 & 30.5 & 0.75 & 0.98 \\
\hline
\end{tabular}

+ resins) from different petroleum crudes can be different. For example, the aromaticity of the aromatic + resin fraction of the heaviest SRVR (Tempa Rossa) is similar to that of the asphaltene fraction from the lightest SRVR analyzed in this work (Caspian Pipeline Consortium crude oil-CPC). It is interesting to note here that the denser SRVRs are characterized by a higher average number of the total rings in the asphaltenes reaching a value of 25 , whereas the lowest total ring number for the asphaltenes from the CPC crude is 12.

By the use of the data for the SRVR density and asphaltene density obtained in the LNB Research laboratory, along with the SARA data and using eqs 8-12, information about density, aromatic carbon fraction, total ring number of the aromatic + resin fraction, and of the asphaltenes can be derived. Table S1 includes SARA and density data for 139 SRVR from 22 literature sources, along with the estimated densities of asphaltenes by eq 10, the estimated density of the aromatic + resin fraction by eq 12 , the estimated CII by eq 1 , and the estimated aromatic structure (aromatics + resins + asphaltenes) content by eq 5 . InterCriteria analysis is described in detail in the Supporting Information.

As a result of running the data in Table S1 through the ICrA software application ${ }^{69,71-81}$ (Tables S4 and S5), besides the known relations of the SRVR density to the aromatic structure content and the saturate content, respectively, a statistically meaningful positive weak consonance $(\mu=0.75)$ was detected between the SRVR saturate content and the CII. By a detailed examination of the data in Table S1, we found that the CII strongly correlates with the SRVR saturate content for those SRVRs that have asphaltene content lower than 14\% (Figure S2a), whereas the SRVRs having asphaltene content higher than $14 \%$ showed a weak relation of CII to the asphaltene content (Figure $4 \mathrm{~b}$ ). The interesting point here is that the maximum CII for the SRVRs, which have lower than 14\% asphaltene content, is higher than 2.0, while the maximum CII for the SRVRs, which have higher than $14 \%$ asphaltene content, is lower than 0.9. This suggests that the higher saturate content SRVRs would demonstrate a lower conversion level in the commercial ebullated-bed hydrocracker, based on the established negative statistically meaningful relation to the VR CII. ${ }^{53}$ The higher influence of the saturate content on the oil colloidal instability is also supported by the finding of Xiong et al. $^{82}$ that light oils are more susceptible to cause asphaltene deposition than heavy oils.

Considering all VR properties from Table S1, an evaluation by ICrA for the expected best- and worst-performing EBVR feeds was carried out. The benchmarks were the properties of the best- and worst-performing SRVR EBVR feeds in the LNB H-Oil VR hydrocracker. The degree of similarity was quantified by the ICrA parameter $\mu$. For values of $\mu \geq 0.95$, SRVRs were considered very close to those of the best and worst performers. Table 3 summarizes the results from the ICrA showing SRVRs from Table S1 that could be expected as the best and as the worst performers. It should be pointed out here that the more the characteristics of the SRVRs are available the more accurate the evaluation by ICra would be. A typical correlation analysis is not capable of giving a quantitative assessment of the degree of similarity between the investigated objects.

The investigations performed at the LNB hydrocracker disprove the statement of Chung and $\mathrm{Xu}$ during studying ebullated-bed vacuum residue hydrocracking ${ }^{83}$ that SARA data by themselves were interesting but the usefulness of SARA data was not proven. The CII of the hydrocracker VR feed is found to be statistically meaningful and negatively affects the conversion level and the yields of high-value products when the LHSV is within the range of $0.17-0.25 \mathrm{~h}^{-1}$. In this case, the hydrocracker conversion level is controlled by the reaction temperature. The processing of VR feeds, which have a higher CII, requires a lower hydrocracking reaction temperature to keep the sediment level in the hydrocracked residual oils within the acceptable limit of not higher than $0.4 \%$. However, the reduction of the LHSV by 2.5 times of the design LHSV seems to allow the processing of higher CII VR feeds and achieve a very high conversion level (93\%) without experiencing increased sediment formation. The lower LHSV allows the feed to contact with a higher amount of the catalyst, which is known to suppress the sediment formation by decreasing the rate of radical recombination reactions leading to the formation of higher molecular lower solubility species. ${ }^{48}$ Therefore, the sediment formation in the ebullated-bed vacuum residue hydrocracking is a complex phenomenon that is affected by the colloidal instability of the feed and also 


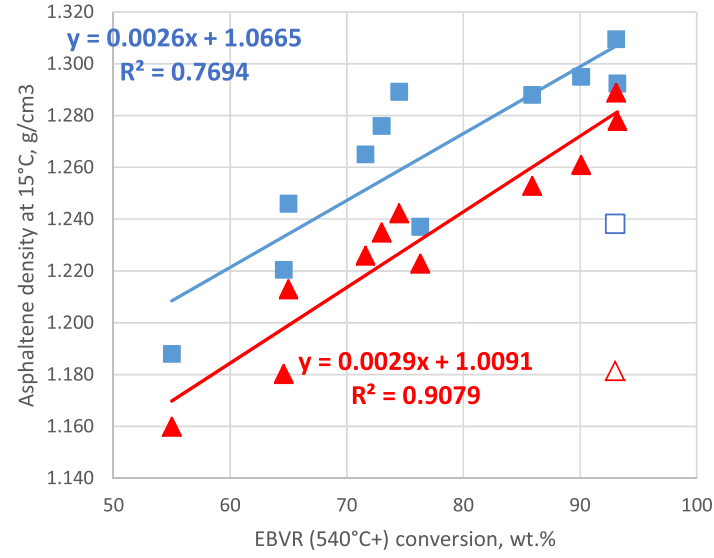

- C7 asp. Density at $15^{\circ} \mathrm{C}, \mathrm{g} / \mathrm{cm} 3 \quad \Delta \mathrm{C} 5$ asp. Density at $15^{\circ} \mathrm{C}, \mathrm{g} / \mathrm{cm} 3$ $\Delta$ Mo nano dispersed catalyst $\mathrm{C} 5$ asp $\square$ Mo nano dispersed catalyst $\mathrm{C7}$ asp

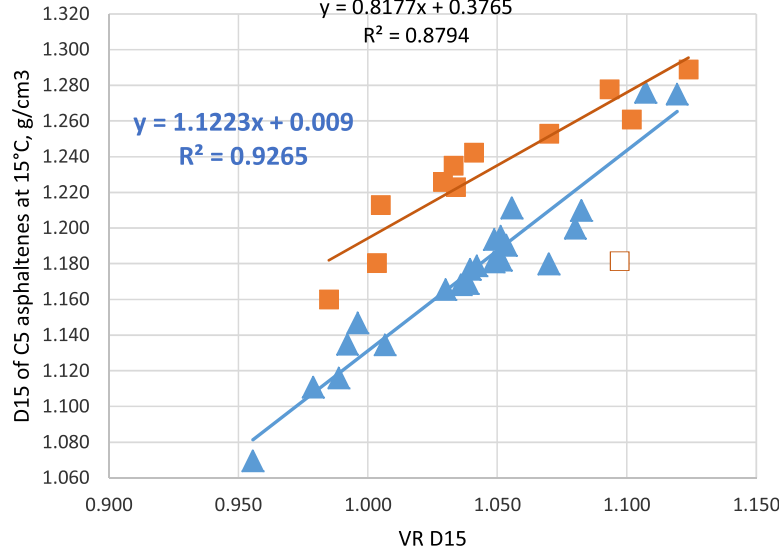

$\triangle$ SRVR C5 asp D15 C5 asp. Density at $15^{\circ} \mathrm{C}, \mathrm{g} / \mathrm{cm} 3$

$\square$ Mo nano dispersed catalyst

Figure 5. Effect of conversion variation in the EBVR hydrocracking on the asphaltene density (a) and the relation of the $\mathrm{C}_{5}$ asphaltene density to the SRVR and VTB densities (b).

by radical scavenging characteristics of the catalytic system. The presence of free radicals in the asphaltene fractions was documented in several recent studies, ${ }^{83-86}$ and their possible participation in the mechanism of asphaltene aggregation and sediment formation was addressed. ${ }^{87}$

Another interesting finding in this study is that the aromatic carbon fractions and the most aromatic part of them, the asphaltenes, become more aromatic (denser) with the increase of the aromaticity (density) of the whole VR (Figure 5). The higher density (aromaticity) means a higher solubility parameter $^{88,89}$ and therefore lower solubility in fluids reach is saturates. On the other hand, the higher aromaticity (density) suggests the presence of free radicals, which can be more stable. ${ }^{87}$ All these factors facilitate the asphaltene aggregation and sediment formation that can take place in the ebullatedbed vacuum residue hydrocracking.

The monitoring of the sediment content in the hydrocracked residual oils (ATB and VTB) is the tool that controls hydrocracker severity, and consequently, conversion level and the yields of high-value products. The measurement of the hydrocracked VTB sediment content may report strange values due to the higher viscosity of this product. Hence, in the commercial hydrocracker, the sediment content of hydrocracked ATB is monitored. The implication of the amount of the sediment content in the hydrocracked ATB for the fouling rate of the equipment in the ebullated-bed hydrocracker is best illustrated in Figure S3. Case 2 (Table 2) is characterized by an extremely high sediment content in the hydrocracked ATB, and a 2 -day operation at the conditions of case 2 was sufficient to shut down the ebullated-bed hydrocracker for 2 weeks for cleaning of the equipment. ${ }^{59}$ By not being in operation for 1 day, the ebullated-bed hydrocracker experiences a loss of about $600 \mathrm{KUSD} /$ day. $^{61}$ Except for case 2, all other 11 cases are characterized with the hydrocracked ATB sediment content not higher than $0.4 \%$.

Evaluating the data in Table 2 by ICrA shows that the conversion level is statistically meaningful and is dependent on the reaction temperature and LHSV. The higher the conversion, the higher is the hydrocracked VTB density, the higher is the Conradson carbon content, the higher is the asphaltene content, the higher are the softening point (SP) and the Fraass breaking point, and the lower is the saturate content (Table S4). The hydrocracked VTB SP strongly correlates with the density, Conradson carbon content, $\mathrm{C}_{5}$ asphaltene content, and the Fraass breaking point. As a whole, one can see that the increase in the conversion makes the hydrocracked VTB denser, harder, and brittle. The relation between the conversion and the hydrocracked VTB density, as well as the relation between density and the other hydrocracked VTB properties, is summarized in the following equations

$$
\begin{aligned}
& \text { VTB D } 15=3 \times 10^{-5} \text {. Conv. }{ }^{2}-0.0014 \text {. Conv. }+0.97, \\
& \quad R^{2}=0.964 \\
& \text { VTB CCR }=181.85 \text { VTB D } 15-163.1, \quad R^{2}=0.960
\end{aligned}
$$

VTB C5asp. $=258.29$. VTB D $15-239.2, \quad R^{2}=0.894$

VTB SP $=2.232$. VTB CCR $-13.3, \quad R^{2}=0.953$

VTB Fraass breaking point $=0.0102$. VTB $\mathrm{SP}^{2}$

$$
\text { - 1066. VTB SP }-22.3, \quad R^{2}=0.957
$$

where VTB D15 is the density of the hydrocracked VTB, g/ $\mathrm{cm}^{3}$ at $15^{\circ} \mathrm{C}$; VTB CCR is the hydrocracked VTB Conradson carbon content, wt \%; VTB $\mathrm{C}_{5}$ asp. is the hydrocracked VTB $\mathrm{C}_{5}$ asphaltene content, wt \%; VTB SP is the hydrocracked VTB softening point, ${ }^{\circ} \mathrm{C}$; and Conv. is the hydrocracker conversion, wt $\%$.

Unlike the VR feed CII that was found to relate to the conversion level, the hydrocracked VTB (ATB) sediment content was not found to correlate with the VTB CII. The ratio of $\mathrm{C}_{5}$ to $\mathrm{C}_{7}$ asphaltenes in the hydrocracked VTB is almost the same as that of the SRVRs, as shown in Figure 4 and reported by Storm et al. ${ }^{93}$ to correlate with the sediment content during hydroprocessing of vacuum residues. Neither the fractionation of the asphaltene fraction in the hydrocracked residual oil designated the hydrocracked VTB asphaltene fraction as easy to dissolve or difficult to dissolve, ${ }^{94}$ nor the 
Table 4. Properties of Hydrocracked VTB from Case 9 with Different Cut Points and the Properties of SRVR Before and After Oxidation

\begin{tabular}{|c|c|c|c|c|c|}
\hline $\begin{array}{l}\text { hydrocracked VTB cut point, } \\
{ }^{\circ} \mathrm{C}\end{array}$ & $\begin{array}{l}\text { soft. } \\
\text { pont, }{ }^{\circ} \mathrm{C}\end{array}$ & $\begin{array}{l}\text { Fraas breaking } \\
\text { point, }{ }^{\circ} \mathrm{C}\end{array}$ & $\begin{array}{c}\Delta \mathrm{SP},{ }^{\circ} \mathrm{C} \text { (increasing of the softening point after the } \\
\text { rolling thin furnace test) }\end{array}$ & $\begin{array}{l}\text { Conradson } \\
\text { content, wt } \%\end{array}$ & $\begin{array}{l}\text { penetration at } \\
25{ }^{\circ} \mathrm{C}, \mathrm{dmm}\end{array}$ \\
\hline 490 & 38.1 & -14 & 13.2 & 25.1 & 165 \\
\hline 500 & 49 & -10 & & 26.6 & \\
\hline 510 & 56 & -4 & 7.8 & 25.7 & 38 \\
\hline 540 & 77.4 & 25 & 8.6 & 36.03 & 5 \\
\hline \multicolumn{6}{|l|}{ SRVR cut point } \\
\hline 540 & 42 & -18 & 4 & 19.0 & 240 \\
\hline \multicolumn{6}{|l|}{$\begin{array}{l}\text { SRVR at } 540{ }^{\circ} \mathrm{C} \text { cut point after } \\
\text { oxidation }\end{array}$} \\
\hline 540 & 51.2 & -16 & 7 & 20.0 & 49 \\
\hline
\end{tabular}

hydrocracked VTB (ATB) asphaltene content was found to correlate with the sediment content in the hydrocracked residual oils. Nevertheless, the removal of asphaltenes from the hydrocracked VTB based on the partially blended fuel oil (PBFO) and the blending of the deasphalted PBFO with the highly saturated content of middle distillates did not produce any sediments as measured by IP 375 and IP 390, ${ }^{95}$ suggesting that the colloidal behavior of the asphaltenes has its role in the process of sediment formation. Additional investigations are needed to be performed and explore the concept of the role of free radicals in the process of asphaltene aggregation and consequently sediment formation, as suggested in ref $84-87$.

As evident from the data in Table 2 and the derived thereof eqs $13-17$, the quality of the hydrocracked VTB as a component for the production of fuel oil and as a component for the production of road asphalt gets worse with the increase of conversion. The sulfur content is far away from the cap of $0.5 \%$ specified by International Maritime Organization (IMO), and the density and Conradson carbon content are much higher than the maximum limit values for fuel oil, i.e., $1.025 \mathrm{~g} /$ $\mathrm{cm}^{3}$ at $15{ }^{\circ} \mathrm{C}$ and $18 \mathrm{wt} \%$. The very high values of the softening point and the Fraass breaking point embarrass the increasing amount of the hydrocracked VTB in the feed for the production of road asphalt. Our recent study ${ }^{51}$ showed that by the addition of fluid catalytic cracking slurry oil (FCC SLO) to the hydrocracked VTB, the rheological properties can be improved. However, the FCC SLO impairs the oxidative aging characteristics of the hydrocracked VTB. Moreover, the hydrocracked VTB is characterized by a higher oxidation rate than the straight run vacuum residues that leads to accelerated oxidative aging. By the addition of sulfur at a concentration of $1.5-2 \%$, the oxidative aging of the hydrocracked VTB can be suppressed. However, the other rheological properties need to be improved to use the hydrocracked VTB as a feed for the production of road asphalt. To investigate the effect of undercutting the hydrocracked VTB and leaving some material boiling in the range of the heavy vacuum gas oil (HVGO) in the hydrocracked ATB from case 9 was fractionated in a laboratory vacuum distillation unit, operating according to ASTM D-5236. The distillation characteristics of the hydrocracked ATB from case 9, measured in accordance with ASTM D-5236 and ASTM D-7169 (high-temperature simulation distillation = HTSD), and the density of the hydrocracked ATB are summarized in Table S5. Table 3 summarizes the properties of the hydrocracked VTB from case 9 with different cut points. Table 3 also contains data for SRVR before and after oxidation that is used as a feed for the production of road asphalt for comparison. These data indicate that both the softening point and the Fraass breaking point linearly decrease with the hydrocracked VTB cut point reduction, whereas the penetration exponentially decreases with hydrocracked VTB cut point reduction. The oxidative aging that is measured by $\Delta S P$ (the increase of the softening point after oxidation at 163 ${ }^{\circ} \mathrm{C}$ for $24 \mathrm{~h}$ in a rolling thin-film oven (RTFO)) shows that, as known from our earlier studies, ${ }^{51-54}$ the hydrocracked VTB has poor resistance to oxidative aging (higher $\Delta \mathrm{SP}$ ). The undercutting while improving the softening point, Fraass breaking point, and penetration seems to deteriorate the hydrocracked VTB resistance to hardening. Therefore, additional treatment is required to keep the specified limit for $\Delta \mathrm{SP}$ not higher than $9{ }^{\circ} \mathrm{C}$ when the amount of hydrocracked VTB in the feed for the production of road asphalt higher than $20 \%$ is desired to increase.

The data in Table 2 show that the hydrocracked vacuum residues of the 12 studied cases are different in $T_{50 \%}$ and heavy vacuum gas oil (HVGO) $T_{95 \%}$, which is an indicator for different VTB cut points. Equations were developed to relate the laboratory ASTM D-5236 vacuum distillation cut point to the content of the material boiling below $540{ }^{\circ} \mathrm{C}$ in VTB and VTB $T_{50 \%}$ on the basis of the results from the laboratory ASTM D-5236 vacuum distillation of the VTB from case 9 (Table 4). They are shown below

$$
\begin{aligned}
& \text { VTB cut point }=-0.0405 \mathrm{VTB}(540)^{2}+0.6306 \mathrm{VTB}(540) \\
& \quad+548.3, \quad R^{2}=0.986 \\
& \text { VTB cut point }=-0.0306 \mathrm{VTB}(\mathrm{T} 50)^{2} \\
& \quad+36.032 \mathrm{VTB}(\mathrm{T} 50)-10058, \quad R^{2}=0.978
\end{aligned}
$$

where VTB cut point is the VTB cut point determined in a laboratory ASTM D-5236 vacuum distillation apparatus, ${ }^{\circ} \mathrm{C}$ and $\operatorname{VTB}(540)$ is the VTB boiling material below $540{ }^{\circ} \mathrm{C}$ according to HTSD (ASTM D 7169), wt \%.

The values for VTB cut point in Table 2 have been estimated by eq 19 .

Case 12 in this study is related to the use of a Mo nanodispersed catalyst. Its use in case 12 was aimed at the investigation of any improvement in the hydrocracked vacuum residual properties. In fact, the softening point and the viscosity of VTB in case 12 decreased. However, case 12 was characterized by a lower VTB cut point of $496{ }^{\circ} \mathrm{C}$ versus 520 ${ }^{\circ} \mathrm{C}$ of case 11 , which operated at the same reaction operating conditions without using the Mo nanodispersed catalyst. To better judge the effect of using a nanocatalyst, the properties of ATB for cases 11 and 12 were measured. They are summarized in Table S8. It is evident from the data in Table S8 that the density and sediment content are lower, while the $\mathrm{Kw}$ - 
characterization factor is higher for the ATB from case 11 . This indicates that the use of the Mo nanodispersed catalyst improves hydrogenation that leads to a lower sediment content and lower density of the EBVR hydrocracked residual oils. Figure 5 shows that the Mo nanodispersed catalyst also hydrogenates asphaltenes in the hydrocracked residual oils, leading to a lower asphaltene density. The density of petroleum asphaltenes, depending on the petroleum origin reported in the literature, ${ }^{16,96-98}$ varies between 1.075 (crude oil CPC $d_{15}=0.795 \mathrm{~g} / \mathrm{cm}^{3}$; sulfur $\left.=0.55 \%\right)$ and $1.26 \mathrm{~g} / \mathrm{cm}^{3}$ (crude oils Prinos $d_{15}=0.875 \mathrm{~g} / \mathrm{cm}^{3}$; sulfur $=3.55 \%$; Tempa Rossa $d_{15}=0.940 \mathrm{~g} / \mathrm{cm}^{3}$; sulfur $=5.35 \%$;). The SRVR C 5 asphaltene densities investigated in this work varied between 1.07 and $1.276 \mathrm{~g} / \mathrm{cm}^{3}$ (Figure 5a) that fits the reported range of asphaltene density variation. The interesting point here is that both virgin and hydrocracked asphaltene densities correlate with the whole vacuum residue density (Figure 5b). The hydrocracked asphaltenes, however, exhibit higher density and therefore higher aromaticity, at the same whole vacuum residue density, than the virgin asphaltenes. The hydrocracked vacuum residues also showed a higher saturate content at the same density. This is one of the reasons for the lower colloidal stability of the hydrocracked vacuum residues than that of the virgin ones. The sediment formation in the EBVRHC, as was discussed earlier, is also dependent on the LHSV, that is, on the amount of the catalyst the feed vacuum residue contacts with. This suggests that both colloidal stability and radical scavenging promoted by the catalyst play a role in suppressing the sediment formation rate in the ebullated-bed vacuum residue hydrocracking. Additional investigations are needed to establish the significance of all these factors in controlling the sediment formation, and consequently, the liberation of the reaction severity to achieve the maximum VR conversion.

\section{CONCLUSIONS}

The characterization of the vacuum residual oil feeds for the ebullated-bed hydrocracking by SARA analysis estimated on its base colloidal instability index (CII) negatively correlates with the conversion and the yields of high-value products when the hydrocracker LHSV varies in the range of $0.17-0.25 \mathrm{~h}^{-1}$. At an LHSV of $0.10 \mathrm{~h}^{-1}$, the feed quality characterized by the SARA method does not correlate with the conversion and a conversion level of $93 \%$ can be achieved even when the hydrocracker feed contains $29 \%$ hydrocracked vacuum residue recycle. The evaluation of the vacuum residue characterization data by intercriteria analysis revealed that the density, aromatic structures, and saturate contents strongly correlate with each other and that the saturate content is the factor that controls the CII of the SRVRs, which have asphaltene content below 14\%. The higher saturate content SRVRs have much higher CII than the higher asphaltene content (>14\%) SRVRs, confirming the finding that light oils are more susceptible to cause asphaltene deposition than heavy oils. The developed equations that relate the VR density to the aromatic structure content or saturate content can be used as a tool to control the correctness of the performed SARA analysis. Deviations in the saturate content or aromatic structure content from the values estimated by the developed equations of more than 4\% (abs) should be considered suspicious and repetition of SARA analysis is recommended. Among the four SARA analysis techniques tested in this work, TLC-Iatroscan showed the maximum deviation from the developed equations to relate the density to the aromatic structure content. Additional studies are required to better elucidate the phenomenon of sediment formation in commercial hydrocracking, exploring the concept of the role of the free radicals in the process of asphaltene aggregation and consequently sediment formation.

The ICrA allows multiple VRO characteristics based on previous EBVRHC experience, quantitatively distinguishing those VROs that are expected to perform good, intermediary, or poor in EBVRHC.

The increase of vacuum residue conversion leads to augmentation of the hydrocracked vacuum residue density, Conradson carbon content, softening point, and Fraass breaking point. The hydrocracked vacuum residue undercutting linearly decreases the softening point, Fraass breaking point, and exponentially reduces the penetration.

The use of the Mo nanodispersed catalyst in the ebullatedbed vacuum residue hydrocracking increases the hydrogenation and as a consequence decreases the density of the whole hydrocracked residual oil and the density of the asphaltene fraction.

\section{EXPERIMENTAL SECTION}

Twelve different cases of the operation of the LNB ebullatedbed vacuum residue hydrocracker have been investigated. The most affecting conversion yields hydrocracker operating conditions (reaction temperature and LHSV) along with the properties of the feeds for these 12 cases, employing methods available in the LNB refinery (Table 1). Table 2 presents data about the properties of the hydrocracked vacuum residues (VTB = vacuum tower bottom) obtained during hydrocracking of the feeds from the 12 cases shown in Table 1 . The methods used to characterize VR oils applied in the LNB refinery are explained in detail in our earlier studies. ${ }^{9,28,57,58}$ The density of the feedstocks and hydrocracked VTB was measured indirectly from the densities of a series of solutions of the vacuum residual oils in toluene at different concentrations as described in refs 57, 58. Solutions of the VR oils in toluene at concentrations up to a VR mass fraction of $6 \%$, solutions of asphaltene in toluene at concentrations up to an asphaltene mass fraction of $3 \%$ were prepared. This way of acting was selected to avoid possible errors in the measurement of the densities of the investigated vacuum residual oils as documented in ref 9. The repeatability of the density measurement by dilution with toluene for the VR oils was $0.0035 \mathrm{~g} / \mathrm{cm}^{3}$, and the repeatability of the density of $\mathrm{C}_{5^{-}}$. asphaltenes was determined to be $\pm 0.023 \mathrm{~g} / \mathrm{cm}^{3}$, while that of $\mathrm{C}_{7}$-asphaltenes was $\pm 0.036 \mathrm{~g} / \mathrm{cm}^{3}$. The Conradson carbon content of the studied vacuum residual oils was measured according to the ASTM D189 method. The softening point of the hydrocracked VR oils in this study was measured according to the ASTM D6493 method. The hydrocracked VR oil Engler specific viscosity was measured in accordance with the ASTM D1665 method at $140{ }^{\circ} \mathrm{C}$. The Fraass breaking point of the hydrocracked VR oils was measured in accordance with EN 12593.

A simplified process diagram of the LNB EBR hydrocracker with the typical range of the operating condition variations is presented in ref 59. The catalyst employed in this study was a commercial $\mathrm{Ni}-\mathrm{Mo}$ low sediment catalyst. The vacuum residue $540{ }^{\circ} \mathrm{C}+$ conversion was estimated by the following equation 


$$
\begin{aligned}
& \text { conversion }(\%) \\
& =\frac{\text { EBRHCFeed }_{540{ }^{\circ} \mathrm{C}+}-\text { EBRHCProduct }_{540}{ }^{\circ} \mathrm{C}+}{\mathrm{EBRHCFeed}_{540}{ }^{\circ} \mathrm{C}+} \times 100
\end{aligned}
$$

where EBRHCFeed $540{ }^{\circ} \mathrm{C}+$ is the mass flow rate of the EBVRHC feed fraction boiling above $540{ }^{\circ} \mathrm{C}$ determined by the high-temperature simulated distillation method ASTM D 7169 of the feed and multiplied by the mass flow rate of the feed and EBRHCProduct $540{ }^{\circ} \mathrm{C}+$ is the mass flow rate of the EBVRHC product fraction boiling above $540{ }^{\circ} \mathrm{C}$ determined by the high-temperature simulated distillation method ASTM D 7169 of the liquid product multiplied by the flow rate of the liquid product.

The total sediment existent (TSE) content of the residual oils studied in this work was measured in accordance with the procedure IP 375. The total sediment potential (TSP) of the residual oils studied in this work was measured in accordance with the procedure IP 390.

\section{ASSOCIATED CONTENT}

\section{SI Supporting Information}

The Supporting Information is available free of charge at https://pubs.acs.org/doi/10.1021/acsomega.0c05073.

InterCriteria analysis description; SARA analysis data for 139 straight run vacuum residua; accuracy of the prediction of the VR aromatic structures content; SARA analysis data for Rhemoura SRVR from two tests; $\mu$-value of the evaluation of relations between properties of the SRVR (PDF)

\section{AUTHOR INFORMATION}

\section{Corresponding Author}

Dicho Stratiev - LUKOIL Neftohim Burgas, 8104 Burgas, Bulgaria; 이이.org/0000-0001-7486-0589;

Email: stratiev.dicho@neftochim.bg

\section{Authors}

Svetoslav Nenov - University of Chemical Technology and Metallurgy, 1756 Sofia, Bulgaria

Ivelina Shishkova - LUKOIL Neftohim Burgas, 8104 Burgas, Bulgaria; 이잉.org/0000-0002-3959-9095

Borislav Georgiev - LUKOIL Neftohim Burgas, 8104 Burgas, Bulgaria

Georgi Argirov - LUKOIL Neftohim Burgas, 8104 Burgas, Bulgaria

Rosen Dinkov - LUKOIL Neftohim Burgas, 8104 Burgas, Bulgaria; (1) orcid.org/0000-0002-9772-1845

Dobromir Yordanov - University Prof. Dr. Assen Zlatarov, 8010 Burgas, Bulgaria

Vassia Atanassova - Institute of Biophysics and Biomedical Engineering, Bulgarian Academy of Sciences, Bulgarian Academy of Sciences, 1113 Sofia, Bulgaria

Petar Vassilev - Institute of Biophysics and Biomedical Engineering, Bulgarian Academy of Sciences, Bulgarian Academy of Sciences, 1113 Sofia, Bulgaria

Krassimir Atanassov - University Prof. Dr. Assen Zlatarov, 8010 Burgas, Bulgaria; Institute of Biophysics and Biomedical Engineering, Bulgarian Academy of Sciences, Bulgarian Academy of Sciences, 1113 Sofia, Bulgaria

Complete contact information is available at: https://pubs.acs.org/10.1021/acsomega.0c05073

\section{Notes}

The authors declare no competing financial interest.

\section{ACKNOWLEDGMENTS}

The authors acknowledge the support from the project UNITe BG05M2OP001-1.001-0004/28.02.2018 (2018-2023).

\section{ABBREVIATIONS}

$\begin{array}{ll}\text { AAD } & \text { average absolute deviation } \\ \text { ATB } & \text { atmospheric tower bottom product } \\ \text { BL } & \text { Basrah light crude oil } \\ \text { CII } & \text { colloidal instability index } \\ \text { CPC } & \text { Caspian Pipeline Consortium crude oil } \\ \text { EBVRHC } & \text { ebullated-bed vacuum residue hydrocracking } \\ \text { Forties } & \text { Forties crude oil } \\ \text { HPLC } & \text { high-performance liquid chromatography } \\ \text { HVGO } & \text { heavy vacuum gas oil } \\ \text { ICrA } & \text { Intercriteria analysis } \\ \text { Kirkuk } & \text { Kirkuk crude oil } \\ \text { LHSV } & \text { liquid hourly space velocity } \\ \text { LNB } & \text { LUKOIL Neftohim Burgas refinery } \\ \text { LSCO } & \text { light Siberian crude oil } \\ \text { MD } & \text { maximum deviation } \\ \text { ME } & \text { Middle East crude oil (Basrah Light or Arabian } \\ & \text { Medium) } \\ \text { Prinos } & \text { Prinos crude oil } \\ \text { SARA } & \text { saturates, aromatics, resins, asphaltenes } \\ \text { SRVR } & \text { straight run vacuum residue } \\ \text { RTFO } & \text { rolling thin-film oven } \\ \text { TLC } & \text { thin-layer chromatography } \\ \text { Ur } & \text { Urals crude oil } \\ \text { VR } & \text { vacuum residue } \\ \text { VTB } & \text { vacuum tower bottom product } \\ & \end{array}$

\section{REFERENCES}

(1) European Expert Group on Future Transport Fuels. Future Transport Fuels, 2011, https://www.google.com/search?q= expected+reduction + in + the + use + of + petroleum + derived+transporta tion + fuels\&rlz=1C1GCEU_bgBG840BG841\&oq= expected+reduction+in+the+use+of+petroleum+derived+transporta tion + fuels\&aqs $=$ chrome..69i57.27903j0j7\&sourceid $=$ chrome\&ie $=$ UTF-8 (accessed Sept 9, 2020).

(2) Panariti, N.; Rispoli, G.In The First EST Commercial Unit: Achieving the Goal of Residue Conversion, 13th International Bottom of the Barrel Conference, 13-14 May, Istanbul, Turkey, 2015.

(3) Stratiev, D.; Nenov, S.; Shishkova, I.; Argirov, G.; Georgiev, B.; Yordanov, D.; Atanassova, V.; Atanassov, K. Non-LinearLeast-Squares Methods for Modelling Vacuum Residue Hydrocracking Selectivity data. Egypt. J. Pet., Submitted for publication.

(4) Prajapati, R.; Kohli, K.; Maity, S. K. Residue Upgradation with Slurry Phase Catalyst: Effect of Feedstock Properties. Fuel 2019, 239, $452-460$.

(5) Mitkova, M.; Stratiev, D.; Shishkova, I.; Dobrev, D. Thermal and Thermo-Catalytic Processes for Heavy Oil Conversion; Professor Marin Drinov Publishing House of Bulgarian Academy of Sciences: Sofia, Bulgaria, 2017.

(6) Stratiev, D.; Shishkova, I.; Kolev, I.; Yordanov, D.; Toteva, V. Petroleum Crude Slate Effect on H-Oil Performance. Int. J. Oil, Gas Coal Technol. 2020, Article in press.

(7) Stratiev, D.; Shishkova, I.; Tankov, I.; Pavlova, A. Challenges in Characterization of Residual Oils. A review. J. Pet. Sci. Eng. 2019, 178, 227-250.

(8) Carbognani, L.; Carbognani-Arambarri, L.; Lopez-Linares, F.; Pereira-Almao, P. Suitable Density Determination for Heavy Hydrocarbons by Solution Pycnometry: Virgin and Thermal Cracked 
Athabasca Vacuum Residue Fractions. Energy Fuels 2011, 25, 36633670.

(9) Stratiev, D.; Shishkova, I.; Nikolaychuk, E.; Atanasova, V.; Atanassov, K. Investigation of Relations of Properties of Straight Run and H-Oil Unconverted Vacuum Residual Oils. Pet. Coal 2019, 61, 763-776.

(10) Yarranton, H. W.; Okafor, J. C.; Ortiz, D. P.; van den Berg, F. G. A. Density and Refractive Index of Petroleum, Cuts, and Mixtures. Energy Fuels 2015, 29, 5723-5736.

(11) Bissada, K. K.; Tan, J.; Szymczyk, E.; Darnell, M.; Mei, M. Group-Type Characterization of Crude Oil and Bitumen. Part I: Enhanced Separation and Quantification of Saturates, Aromatics, Resins and Asphaltenes (SARA). Org. Geochem. 2016, 95, 21-28.

(12) Fan, T. G.; Buckley, J. S. Rapid and Accurate SARA Analysis of Medium Gravity Crude Oils. Energy Fuels 2002, 16, 1571-1575.

(13) Hauser, A.; Alhumaidan, F.; Al-Rabiah, H.; Absi Halabi, M. Study on Thermal Cracking of Kuwaiti Heavy Oil (vacuum residue) and Its SARA Fractions by NMR Spectroscopy. Energy Fuels 2014, 28, 4321-4332.

(14) Kharrat, A. M.; Zacharia, J.; Cherian, V. J.; Anyatonwu, A. Issues with Comparing SARA Methodologies. Energy Fuels 2007, 21, 3618-3621.

(15) Klein, G. C.; Angstrom, A.; Rodgers, R. P.; Marshall, A. G. Use of Saturates/Aromatics/ Resins/Asphaltenes (SARA) Fractionation to Determine Matrix Effects in Crude Oil Analysis by Electrospray Ionization Fourier Transform, Ion Cyclotron Resonance Mass Spectrometry. Energy Fuels 2006, 20, 668-672.

(16) León, A. Y.; Parra, M.; Grosso, J. L. Estimation of Critical Properties of Typically Colombian Vacuum Residue SARA Fraction. CT\&F, Cienc., Tecnol. Futuro 2008, 3, 129-142.

(17) León, A. Y.; Parra, M. J. Determination of Molecular Weight of Vacuum Residue and Their SARA Fractions. CT\&F, Cienc., Tecnol. Futuro 2010, 4, 101-112.

(18) Wu, W.; Saidian, M.; Gau, S.; Prasad, M. In Errors and Repeatability in VSARA Analysis of Heavy Oils, SPE Heavy Oil Conference, 12-14 June, Calgary, Canada, 2012.

(19) Youtcheff, J. Automated High-Performance Liquid Chromatography Saturate, Aromatic, Resin, and Asphaltene Separation, Technical Report FHWA-HRT-15-055. Turner-Fairbank Highway Research Center: McLean, VA, 2016.

(20) Corbett, L. W. Composition of Asphalt Based on Generic Fractionation, using Solvent Deasphaltening, Elution-Adsorption Chromatography, and Densimetric Characterization. Anal. Chem. 1969, 41, 576-579.

(21) Boysen, R. B.; Schabron, J. F. The Automated Asphaltene Determinator Coupled with Saturates, Aromatics, and Resins Separation for Petroleum Residua Characterization. Energy Fuels 2013, 27, 4654-4661.

(22) Adams, J. J.; Schabron, J. F.; Boysen, R. Quantitative Vacuum Distillation of Crude Oils to Give Residues Amanable to the Asphaltene Determinator Coupled with Saturates, Aromatics, and Resins Separation Characterization. Energy Fuels 2015, 29, 27742784.

(23) Jiang, C.; Larter, S. R.; Noke, K. J.; Snowdon, L. R. TLC-FID (Iatroscan) Analysis of Heavy Oil and Tar Sand Samples. Org. Geochem. 2008, 39, 1210-1214.

(24) Masson, J.-F.; Price, T.; Collins, P. Dynamics of Bitumen Fractions by Thin-Layer Chromatography/Flame Ionization Detection. Energy Fuels 2001, 15, 955-960.

(25) Abutaqiya, M. I. L.; Sisco, C. J.; Khemka, Y.; Safa, M. A.; Ghloum, E. F.; Rashed, A. M.; Gharbi, R.; Santhanagopalan, S.; AlQahtani, M.; Al-Kandari, E.; Vargas, F. M. Accurate Modeling of Asphaltene Onset Pressure in Crude Oils Under Gas Injection Using Peng-Robinson Equation of State. Energy Fuels 2020, 34, 40554070.

(26) Abutaqiya, M. I. L.; Sisco, C. J.; Wang, J.; Vargas, F. M. Systematic Investigation of Asphaltene Deposition in the Wellbore and Near-Wellbore Region of a Deepwater Oil Reservoir Under Gas
Injection. Part 1: Thermodynamic Modeling of the Phase Behavior of Polydisperse Asphaltenes. Energy Fuels 2019, 33, 3632-3644.

(27) Sisco, C. J.; Abutaqiya, M. I. L.; Wang, F.; Zhang, J.; Tavakkoli, M.; Vargas, F. M. Asphaltene Precipitation Modeling. In Asphaltene Deposition: Fundamentals, Prediction, Prevention, and Remediation, 1st ed.; CRC Press: Boca Raton, FL, 2018; pp 111-159.

(28) Stratiev, D.; Shishkova, I.; Nikolova, R.; Tsaneva, T.; Mitkova, M.; Yordanov, D. Investigation on Precision of Determination of SARA Analysis of Vacuum Residual Oils from Different Origin. Pet. Coal 2016, 58, 109-119.

(29) ASTMD-4124. Standard Test Method for Separation of Asphalt into Four Fractions.

(30) Zhao, S.; Xu, Z.; Xu, C.; Chung, K. H. Feedstock Characteristic Index and Critical Properties of Heavy Crudes and Petroleum Residua. J. Pet. Sci. Eng. 2004, 41, 233-242.

(31) Stratiev, D.; Petkov, K. Residue Upgrading - Challenges and Perspectives. Hydrocarbon Process. 2009, 93-97.

(32) Singh, J.; Kumar, M. M.; Saxena, A. K.; Kumar, S. Studies on Thermal Cracking Behavior of Residual Feedstocks in a Batch Reactor. Chem. Eng. Sci. 2004, 59, 4505-4515.

(33) Schabron, J. F.; Gardner, G. W.; Hart, J. K.; Niss, N. D. The Characterization of Petroleum Residua; Western Research Institute, 1993.

(34) Akbarzadeh, K.; Alboudwarej, H.; et al. A Generalized Regular Solution Model for Asphaltene Precipitation from n-Alkane Diluted Heavy Oils and Bitumens. Fluid Phase Equilib. 2005, 232, 159-170.

(35) Xu, C.; Gao, J.; Zhao, S.; Lin, S. Correlation Between Feedstock SARA Components and FCC Product Yields. Fuel 2005, 84, 669674.

(36) Liu, C.; Zhou, J.; Clue, G.; Liang, W.; Zhu, Y. Hydrocracking of Gudao Residue with Dispersed-Phase Mo Catalyst. Fuel 1994, 73, 1544-1550

(37) Rezaei, H.; Liu, X.; Ardakani, S. J.; Smith, K. J.; Bricker, M. A study of Cold Lake Vacuum Residue Hydroconversion in Batch and Semi-Batch Reactors Using Unsupported MoS2 Catalysts. Catal. Today 2010, 150, 244-254.

(38) Parviz, M. R.; Gentzis, Th. The Chemistry of Bitumen and Heavy Oil Processing. Practical Advances in Petroleum Processing; Springer, 2006; Chapter 19, pp 19-634.

(39) Wang, H.; Wang, G.; Shen, B.; Xu, C.; Gao, J. Upgrading Residue by Carbon Rejection in a Fluidized-Bed Reactor and Its Multiple Lump Kinetic Model. Ind. Eng. Chem. Res. 2011, 50, 1250112511.

(40) Chen, K.; Wang, Z.; Liu, H.; Guo, A. Study on Thermal Performance of Heavy Oils by Using Differential Scanning Calorimetry. Fuel Process. Technol. 2012, 99, 82-89.

(41) Hong, E.; Watkinson, P. A Study of Asphaltene Solubility and Precipitation. Fuel 2004, 83, 1881-1887.

(42) Yang, C.; Du, F.; Zheng, H.; Chung, K. H. Hydroconversion Characteristics and Kinetics of Residue Narrow Fractions. Fuel 2005, $84,675-684$.

(43) Guo, A.; Zhang, X.; Zhang, H.; Wang, Z.; Wang, Z. Aromatization of Naphthenic Ring Structures and Relationships between Feed Composition and Coke Formation during Heavy Oil Carbonization. Energy Fuels 2010, 24, 525-532.

(44) Hinkle, A.; Shin, E.-J.; Liberatore, M. W.; Herring, A. M.; Batzlea, M. Correlating the Chemical and Physical Properties of a Set of Heavy Oils from Around the World. Fuel 2008, 87, 3065-3070.

(45) Peralta-Martínez, M. V.; García-Trujillo, M. E.; PalaciosLozano, E. M.; Blass-Amador, G. The Effect of SARA Fractions on Viscosity for Five Mexican Vacuum Residues. Energy Sources, Part A 2011, 33, 920-924.

(46) León, A.-Y.; Guzmán, A.; Picón, H.; Laverde, D.; Molina, D. Reactivity of Vacuum Residues by Thermogravimetric Analysis and Nuclear Magnetic Resonance Spectroscopy. Energy Fuels 2020, 34, 9231-9242.

(47) Molina, D.; Uribe, U. N.; Murgich, J. Correlations Between SARA Fractions and Physicochemical Properties with $1 \mathrm{H}$ NMR 
Spectra of Vacuum Residues from Colombian Crude Oils. Fuel 2010, 89, 185-192.

(48) Fortain, D. Étude de la Réactivité des Résidus Pétroliers en Hydroconversion. Ph.D. Thesis, l'Université Bordeaux, 2010.

(49) Marques, J.; Maget, S.; Verstraete, J. J. Improvement of Ebullated Bed Effluent Stability at High Conversion Operation. Energy Fuels 2011, 25, 3867-3874.

(50) Dinkov, R.; Stratiev, D.; Stanulov, K.; Mitkova, M.; Georgiev, K.; Veli, A. Investigation on Relationship Between Physicochemical Properties of Vacuum Residual Oils and Their Content of Aromatic Constituents. Erdöl Erdgas Kohle 2014, 5, 195-199.

(51) Dinkov, R.; Kirilov, K.; Stratiev, D.; Sharafutdinov, I.; Dobrev, D.; Nguyen-Hong, D.; Chapot, S.; Le-coz, J. F.; Burilkova, A.; Bakalova, D.; Yordanov, D.; Smilkov, S. Feasibility of Bitumen Production from Unconverted Vacuum Tower Bottom from H-Oil Ebullated Bed Residue Hydrocracking. Ind. Eng. Chem. Res. 2018, 57, 2003-2013.

(52) Stratiev, D.; Shishkova, I.; Dinkov, R.; Kirilov, K.; Yordanov, D.; Nikolova, R.; Veli, A.; Tavlieva, M.; Vasilev, S.; Suyunov, R. Variation of Oxidation Reactivity of Straight Run and H-Oil Hydrocracked Vacuum Residual Oils in the Process of Road Asphalt Production. Road Mater. Pavement Des, Submitted for publication.

(53) Dinkov, R.; Stratiev, D.; Shishkova, I.; Veli, A.; Nikolova, R.; Yordanov, D.; Ilchev, I. Opportunity to Increase the Share of Unconverted Vacuum Tower Bottom from Residue Hydrocracking (H-Oil) in Paving Grade Bitumen Production. Oxid. Commun. 2020, 43, 302-320.

(54) Stratiev, D.; Shishkova, I.; Dinkov, R.; Yordanov, D.; Ilchev, I.; Toteva, V. Effect of H-Oil Hydrocracked Vacuum Residue Quality Variation on the Feasibility to Produce Road Asphalt Thereof. Oxid. Commun. 2020, 43, 545-558.

(55) Suyunov, R.; Gaziev, R.; Dunin, N.; Lazer, M.; Stratiev, D.; Shishkova, I.; Vasilev, S. A Method to Produce Road Pavement Bitumen from a Residue. Russian Patent no. 27211182020.

(56) Stratiev, D.; Shishkova, I.; Argirov, G.; Mountainland, D.; Silverman, B. Improving $\mathrm{H}$-Oil Ebullated Bed Vacuum Residue Hydrocracking Performance By The Use OfMolecularly Dispersed HCAT Catalyst. PTQ Article in press.

(57) Stratiev, D.; Shishkova, I.; Nikolaychuk, E.; Ijlstra, W.; Holmes, B.; Caillot, M. Feed Properties Effect on the Performance of Vacuum Residue Ebullated Bed H-Oil Hydrocracking. Oil Gas Eur. Mag 2019, 4, 194-199.

(58) Stratiev, D.; Shishkova, I.; Ivanova, N.; Veli, A.; Nikolova, R.; Mitkova, M.; Stanulov, K.; Argirov, G.; Yordanov, D.; Nikolaychuk, E. Colloidal Stability and Hot Filtration Test of Residual Fuel Oils Based on Visbreaking and Ebullated Bed Residue H-Oil Hydrocracking. Int. J. Oil, Gas Coal Technol. 2019, 20, 169-188.

(59) Stratiev, D.; Dinkov, R.; Shishkova, I.; Sharafutdinov, I.; Ivanova, N.; Mitkova, M.; Yordanov, D.; Rudnev, N.; Stanulov, K.; Artemiev, A.; Barova, I.; Chushkov, B. What is Behind the High Values of Hot Filtration Test of the Ebullated Bed Residue H-Oil Hydrocracker Residual Oils? Energy Fuels 2016, 30, 7037-7054.

(60) https://www.axens.net/product/process-licensing/20119/hoil-process.html.

(61) Stratiev, D. S.; Shishkova, I. K.; Nikolaychuk, E.; Anastasov, M.; Stanulov, K.; Toteva, V. Effect of Catalyst Condition on Sedimentation and Conversion in the Ebullated Bed Vacuum Residue H-Oil Hydrocracking. Pet. Sci. Technol. 2019, 37, 1463-1470.

(62) Asomaning, S. Test Methods for Determining Asphaltene Stability in Crude Oils. Pet. Sci. Technol. 2003, 21, 581-590.

(63) Hong, E.; Watkinson, P. Precipitation and Fouling in Heavy Oil-Diluent Blends. Heat Transfer Eng. 2009, 30, 786-793.

(64) Nikookar, M.; Omidkhah, M. R.; Pazuki, G. R. Prediction of Density and Solubility Parameter of Heavy Oils and SARA Fractions Using Cubic Equations of State. Pet. Sci. Technol. 2008, 26, 19041912.

(65) Powers, D. P. Characterization and Asphaltene Precipitation Modeling of Native and Reacted Crude Oils. Ph.D. Thesis, University of Calgary: Calgary, Alberta, Canada, 2014.
(66) Greaves, M.; Ayatollahi, S.; Moshfeghian, M.; Alboudwarej, H.; Yarranton, H. W. Estimation of SARA Fraction Properties With the SRK EOS. J. Can. Pet. Technol. 2004, 43, 9.

(67) Das, S.; Suganthan, P. N. Differential Evolution: A Survey of the Stateof- the-Art. IEEE Trans. Evol. Computat. 2011, 15, 4-31.

(68) Vargas, F. M.; Creek, J. L.; Chapman, W. G. On the Development of an Asphaltene Deposition Simulator. Energy Fuels 2010, 24, 2294-2299.

(69) Mullins, O. C. The Modified Yen Model. Energy Fuels 2010, 24, 2179-2207.

(70) Gaspar, A.; Zellermann, E.; Lababidi, S.; Reece, J.; Schrader, W. Characterization of Saturates, Aromatics, Resins, and Asphaltenes Heavy Crude Oil Fractions by Atmospheric Pressure Laser Ionization Fourier Transform Ion Cyclotron Resonance Mass Spectrometry. Energy Fuels 2012, 26, 3481-3487.

(71) Atanassov, K.; Mavrov, D.; Atanassova, V. Intercriteria Decision Making: A New Approach for Multicriteria Decision Making, Based on Index Matrices and Intuitionistic Fuzzy Sets. Intuitionistic Fuzzy Sets Generalized Nets 2014, 11, 1-8.

(72) Stratiev, D.; Shishkova, I.; Nedelchev, A.; Kirilov, K.; Nikolaychuk, E.; Ivanov, A.; Sharafutdinov, I.; Veli, A.; Mitkova, M.; Tsaneva, T.; Petkova, N.; Sharpe, R.; Yordanov, D.; Belchev, Z.; Nenov, S.; Rudnev, N.; Atanassova, V.; Sotirova, E.; Sotirov, S.; Atanassov, K. Investigation of Relationships Between Petroleum Properties and Their Impact on Crude Oil Compatibility. Energy Fuels 2015, 29, 7836-7854.

(73) Atanassov, K. Intuitionistic Fuzzy Sets; VII ITKR's Session, Sofia, 1983 (in Bulgarian).

(74) Atanassov, K. Intuitionistic Fuzzy Sets. Fuzzy Sets Syst. 1986, 20, 87-96.

(75) Atanassov, K. Intuitionistic Fuzzy Sets: Theory and Applications; Springer Physica-Verlag: Heidelberg, Germany, 1999.

(76) Atanassov, K. On Intuitionistic Fuzzy Sets Theory; Springer: Berlin, Germany, 2012.

(77) Atanassov, K. Generalized Index Matrices. Comptes rendus de l'Academie Bulgare des Sciences 1987, 11, 15-18.

(78) Atanassov, K. Index Matrices: Towards an Augmented Matrix Calculus; Springer: Cham, 2014.

(79) InterCriteria Research Portal. 2015, http://www.intercriteria. net/publications.

(80) Mavrov, D. Software for InterCriteria Analysis: Implementation of the main algorithm. Notes on Intuitionistic Fuzzy Sets 2015, 2, 7786.

(81) Atanassov, K.; Atanassova, V.; Gluhchev, G. InterCriteria Analysis: Ideas and problems. Notes on Intuitionistic Fuzzy Sets 2015, $1,81-88$.

(82) Xiong, R.; Guo, J.; Kiyingi, W.; Feng, H.; Sun, T.; Yang, X.; Li, Q. Method for Judging the Stability of Asphaltenes in Crude Oil. ACS Omega 2020, 5, 21420-21427.

(83) Chung, K. H.; Xu, C. Narrow-Cut Characterization Reveals Resid Process Chemistry. Fuel 2001, 80, 1165-1177.

(84) Tannous, J. H.; de Klerk, A. Quantification of the Free Radical Content of Oilsands Bitumen Fractions. Energy Fuels 2019, 33, 70837093.

(85) Alili, A. S.; Siddiquee, M. N.; de Klerk, A. Origin of Free Radical Persistence in Asphaltenes: Cage Effect and Steric Protection. Energy Fuels 2020, 34, 348-359.

(86) Naghizada, N.; Prado, G. H. C.; de Klerk, A. Uncatalyzed Hydrogen Transfer during $100-250{ }^{\circ} \mathrm{C}$ Conversion of Asphaltenes. Energy Fuels 2017, 31, 6800-6811.

(87) Zhang, Y.; Siskin, M.; Gray, M. R.; Walters, C. C.; Rodgers, R. P. Mechanisms of Asphaltene Aggregation: Puzzles and a New Hypothesis. Energy Fuels 2020, 34, 9094-9107.

(88) Rogel, E. Theoretical Estimation of the Solubility Parameter Distributions of Asphaltenes, Resins, and Oils from Crude Oils and Related Materials. Energy Fuels 1997, 11, 920-925.

(89) Rogel, E.; Ovalles, C.; Pradhan, A.; Leung, P.; Chen, N. Sediment Formation in Residue Hydroconversion Processes and its 
Correlation to Asphaltene Behavior. Energy Fuels 2013, 27, 65876593.

(90) van den Berg, F. G. A.; Heijnis, R. M. A.; Stamps, P. A.; Kramer, P. A. A Geochemical Framework for Understanding Residue Properties. Pet. Sci. Technol. 2003, 21, 449-460.

(91) Speight, J. G.; Moschopedis, S. E. On the Molecular Nature of Petroleum Asphaltenes. Adv. Chem. 1982, 195.

(92) Stratiev, D.; Shishkova, I.; Tsaneva, T.; Mitkova, M.; Yordanov, D. Investigation of Relations Between Properties of Vacuum Residual Oils from Different Origin, and of Their Deasphalted and Asphaltene Fractions. Fuel 2016, 170, 115-129.

(93) Storm, D. A.; Decanio, S. J.; Edwards, J. C.; Sheu, E. Y. Sediment Formation During Heavy Oil Upgrading. Pet. Sci. Technol. 1997, 15, 77-102.

(94) Stratiev, D.; Dinkov, R.; Shishkova, I.; Yordanov, D. Can We Manage the Process of Asphaltene Precipitation During the Production of IMO 2020 Fuel Oil? Erdoel Erdgas Kohle 2020, 12, 34-41.

(95) Stratiev, D.; Shishkova, I.; Nikolaychuk, E.; Dinkov, R.; Stoilov, G.; Yankov, V.; Mitkova, M. Impact of Severity in the H-Oil Vacuum Residue Hydrocracking on Sediment Formation. Pet. Coal 2019, 61, 1166-1182.

(96) Rogel, E.; Ovalles, C.; Bake, K. D.; Zuo, J. Y.; Dumont, H.; Pomerantz, A. E.; Mullins, O. Asphaltene Densities and Solubility Parameter Distributions: Impact on Asphaltene Gradients. Energy Fuels 2016, 30, 9132-9140.

(97) Calemma, V.; Rausa, R.; D’Antona, P.; Montanari, L. Characterization of Asphaltenes Molecular Structure. Energy Fuels 1998, 12, 422-428.

(98) Rogel, E.; Carbognani, L. Density Estimation of Asphaltenes Using Molecular Dynamics Simulations. Energy Fuels 2003, 17, 378386. 